\title{
Efficacy and Safety of Peripherally Acting $\mu$ - Opioid Receptor Antagonist (PAMORAs) for the Management of Patients With Opioid-Induced Constipation: A Systematic Review
}

Martina Rekatsina ${ }^{1}$, Antonella Paladini ${ }^{2}$, Asbiørn M. Drewes ${ }^{3}$, Farrah Ayob ${ }^{4}$, Omar Viswanath ${ }^{5}$, Iva Urits $^{6}$, Oscar Corli ${ }^{7}$, Joseph Pergolizzi Jr ${ }^{8}$, Giustino Varrassi ${ }^{9}$

1. Pain Management, Whipps Cross Hospital Barts Health NHS, London, GBR 2. Department of Clinical Medicine, Public Health and Life Science (MESVA), University of L'Aquila, L'Aquila, ITA 3. Department of Gastroenterology and Hepatology, Aalborg University Hospital, Aalborg, DNK 4. Anesthesia, Barts Health, London, GBR 5. Pain Management, Valley Pain Consultants - Envision Physician Services, Phoenix, USA 6. Department of Anesthesia, Critical Care and Pain Medicine, Beth Israel Deaconess Medical Center, Harvard Medical School, Boston, USA 7. Pain and Palliative Care Research Unit, Mario Negri Institute IRCCS, Milano, ITA 8. Research Department, Nema Research, Inc., Naples, USA 9. Research, Paolo Procacci Foundation, Roma, ITA

Corresponding author: Giustino Varrassi, paoloprocaccifoundation@gmail.com

\begin{abstract}
In treating chronic and acute pain, opioids are widely used. Although they do provide analgesia, their usage does come with adverse events (AEs). One of the most burdensome is opioid-induced bowel dysfunction, and more specifically opioid-induced constipation (OIC). The pathogenesis of these AEs is well known as the consequence of the action of opioids on $\mathrm{m}$-receptors in the enteric nervous system. In recent years, medicines counteracting this specific action at the receptors have been registered for clinical use: the peripherally acting $\mu$-opioid receptor antagonists (PAMORAs). The knowledge of their comparative efficacy and tolerability is very important for physicians and patients in opioid therapy. This systematic review of the existing literature on PAMORAs aimed to study the relative clinical advantages and disadvantages.
\end{abstract}

The most important data banks, including "PubMed," "Embase," "CT.gov," "ICTRP" and "CINAHL" were used to find the published material on PAMORAs. The selected publications were examined to systematically analyze the efficacy and safety of the four existing PAMORAs.

All of the medications are superior to placebo in reducing OIC. There are few published data on alvimopan used to treat OIC, and it is only indicated for the treatment of post-abdominal surgery ileus. Methylnaltrexone is studied mainly in its subcutaneous (SC) formulation. When used in its oral formulation, it seems more rapid than naloxegol and placebo in the reduction of OIC. Naldemedine is able to produce more spontaneous bowel movements (SBMs) when compared to alvimopan and naloxegol.

Received 06/14/2021 Review began 06/14/2021 Review ended 07/04/2021 Published 07/05/2021

\section{() Copyright 2021}

Rekatsina et al. This is an open access article distributed under the terms of the Creative Commons Attribution License CC-BY 4.0., which permits unrestricted use, distribution, and reproduction in any medium, provided the original author and source are credited.
Tolerability was found to be similar for all of them. In particular, they affect the gastrointestinal tract (GI), with flatulence and diarrhea, especially at high dosages. For some of them, nasopharyngitis and abdominal pain were observed as treatment adverse effects (TEAs). Several cardiovascular TEAs were reported after methylnaltrexone use, but it is not clear whether they were consequences of the drug or related to the general conditions of the patients.

Considering the existing data, naloxegol and naldemedine seem to be the best choices, with a higher number of spontaneous bowel movements following naldemedine administration.

Categories: Pain Management, Gastroenterology, Other

Keywords: opioids, pain, opioid induced constipation, opioid-induced bowel dysfunction, pamora, peripherally acting m-opioid receptor antagonist

\section{Introduction And Background}

Opioids are powerful analgesics that have been used for centuries in the treatment of acute and chronic cancer and non-cancer pain [1]. Among their common side effects, the most bothersome and debilitating are those associated with opioid-induced bowel dysfunction (OIBD). This includes opioid-induced constipation (OIC) [2,3], defined as a change in baseline bowel habit or defecatory patterns following initiation, modification, or increase of opioid therapy [1]. OIC is a common side effect, yet under-recognized and under-treated [2]. This ongoing burden emphasizes the need to identify more efficacious constipation therapies for the chronic pain patient population treated with opioids [4] as effective pharmacologic therapy for OIC is considered an unmet need [3]. 


\section{Pathogenesis of OIC}

The pathogenesis of OIBD and OIC is attributed to the action of opioids on their receptors in the gastrointestinal tract [1]. Opioid receptors $(\mu, \mathrm{K}$, and $\delta$ ) are spread throughout the gastrointestinal tract (GI) from the mid-esophagus to the rectum and are involved in a variety of cellular functions [5]. In humans, $\mu$ receptors are thought to be of utmost importance for the homeostatic functions of the enteric nervous system [6]. Endogenous ligands play a role in the normal regulation of GI function, but opioid receptors are also activated by exogenous opioids [6,7]. Opioid agonists administration results in modifications of the normal GI physiology, with segmentation, increased tone, and uncoordinated motility reflected in constipation. Also, opioids' administration results in increased absorption and decreased secretion of fluids in the gut, leading to dry feces and less propulsive motility [8]. They increase sphincter tone, which may cause symptoms such as sphincter of Oddi spasms and hampered rectal evacuation [8-10]. Opioid antagonists counteract the effects of opioids in the human gut on motility, fluid transport, and sphincter function [8].

\section{Prevalence of OIC}

OIC is the most common subtype of OIBD that occurs in $51-87 \%$ of patients receiving opioids for cancer and between $41 \%$ and $57 \%$ of patients receiving opioids for chronic noncancer pain [11-13]. A recent "real-world" multicenter, observational study assessed cancer patients on opioids for the prevalence of OIC [14]. The authors utilized some different diagnostic criteria for OIC. They concluded that $59 \%$ of patients had clinical OIC, $2.5 \%$ had another cause of constipation, and $19 \%$ did not have constipation but were assuming laxatives [14]. A multicenter cross-sectional observational study showed that approximately two out of three patients with chronic opioid intake experienced a degree of constipation that was problematic for the patient, while more than four out of five patients were considered constipated according to the physician's subjective assessment despite laxative use [15].

\section{Effects of opioids}

Dose, frequency, and duration of opioid therapy influence the likelihood of OIC symptoms [16]. Bell et al. [17] mentioned that daily use of opioids resulted in constipation in $81 \%$ of patients, whereas patients using opioids two to three times per week reported constipation in less than $50 \%$ of the cases. Moreover, the route of opioid intake seems to play a role, as transdermal preparations of fentanyl and buprenorphine may be associated with a lower incidence of OIC than oral opioids both in cancer and non-cancer patients [18]. Results should, however, be interpreted cautiously as these studies included small patient materials and had several inherent flaws, and no matter what the administration route is the opioids will reach the gut. In addition, OIC does not spontaneously decrease over time due to tolerance (for the colon only) but persists with unchanged prevalence [19].

OIC was not associated with demographic factors, cancer diagnosis, performance status, or opioid dosage. However, it was associated with specific opioid analgesics, namely tramadol, tapentadol, and transdermal buprenorphine which both led to less constipation [14]. The study confirms that OIC is common among patients with cancer pain and is associated with a spectrum of physical symptoms, a range of psychological symptoms, and an overall deterioration in the quality of life [14].

\section{Impact}

OIC could lead to pain exacerbation, longer hospitalization, frequent changes in opioids $[3,15]$ and laxative treatment $[15,20]$, higher healthcare resource utilization, and other extra costs [20,21]. Moreover, OIC has a negative impact on work productivity (as reflected by missed days and impairment while working) as well as health-related quality of life $[3,14,15,17]$.

\section{Diagnosis}

To identify OIC, the Bowel Function Index (BFI), a physician-administered, easy-to-use scale can be utilized to objectively identify patients who need more aggressive treatment $[22,23]$. For research studies, patients meeting the criteria for OIC should not be given a diagnosis of functional constipation (FC) because it is difficult to distinguish between opioid side effects and other causes of constipation. However, clinicians recognize that these two conditions may overlap [24]. The Rome IV diagnostic criteria for opioid-induced constipation is an updated, systematized definition of OIC and is also a very useful tool (Table 1)

[23]. According to a recent observational study, the Rome IV diagnostic criteria had an accuracy of $81.9 \%$, which is extremely high [14]. 


\section{Cureus}

1. New, or escalating, symptoms of constipation when initiating, changing, or increasing opioid therapy that must include two or more of the following:

\section{a. Straining during more than one-quarter of defecations}

b. Lumpy or hard stools (BSFS 1-2) more than one-quarter of the time.

c. Sensation of incomplete evacuation more than one-quarter of the time.

d. Sensation of anorectal blockage/obstruction in more than one-quarter of defecations.

e. Manual maneuvers to facilitate more than one-quarter of defecations.

f. Fewer than three spontaneous bowel movements per week.

2. Loose stools rarely present without the use of laxatives.

TABLE 1: Diagnostic criteria.

Roma IV diagnostic criteria [23].

\section{Management}

After identification of OIC, it is important to assess the patient clinically, identify the reason for an opioid prescription, the current doses as well as differentiate OIC from pre-existing constipation exacerbated by the opioids [1]. Addressing exacerbating factors, including concurrent constipating medications (calcium channel blockers, diuretics, etc.) is also crucial [1]. Some general management could include lifestyle modification (increase fluid intake, exercise) and addition of standard laxatives (osmotic agents and stimulants) although never documented to be beneficial in controlled studies. Change to a different opioid or change route of administration would be a different option, but again the evidence is sparse [18].

Educational strategies need to be developed to improve the knowledge base of healthcare providers on the identification [1] and challenging management of OIC [3]. However, despite early management, constipation might still develop and persist [4].

Should the above be the case, opioid-receptor antagonists can alleviate the adverse effects of opioids on GI functions [25]. Some agents that cross the blood-brain barrier, like naloxone, antagonize the central analgesic effects [25]. Other medicines not crossing this barrier (or are actively transported out of the central nervous system) block only peripheral opioid receptors, including those in the gastrointestinal tract, and have no effect on the central nervous system that may counteract the analgesia. Currently, there are few such medicines, called peripherally acting $\mu$-opioid receptors antagonists (PAMORAs), with peripheral action that seems to be effective and relatively safe $[26,27]$. They are alvimopan, methylnaltrexone, naloxegol, and naldemedine. This systematic review is focused on the efficacy and safety of the abovementioned PAMORAs.

\section{Review}

\section{Material and methods}

The protocol of this study is registered in the protocol on the International Prospective Register of Systematic Reviews (PROSPERO) with registration number CRD42021256185.

\section{Literature Selection Criteria}

We performed an electronic database search in "PubMed," “Embase," "CT.gov," “ICTRP," and "CINAHL" of the publications that appeared before May 1, 2021. We used a series of logic combinations, word variations and research terms related to opioid-induced constipation and PAMORAs in each database. Published systematic reviews on the same topic were reviewed to identify additional randomized controlled trials. An example of the searching strategy was ("Peripherally acting $\mu$-opioid receptor antagonists" or "Naloxegol" or "Alvimopan" or "Naldemedine" or "Methylnaltrexone" or "Axelopran" or "PAMORA") AND "opioid-induced constipation" in Title, Abstract, Keyword.

\section{Inclusion and Exclusion Criteria}

We included only original studies (RCTs, open-label studies and post-hoc analysis of RCTs) that included cancer and/or non-cancer pain patients as well as patients with advanced illness. We did not limit the results to opioid use for pain relief and included, e.g., patients on methadone for addiction. Other 
inclusion criteria were trials including adult patients above 18 years of age, on stable opioid doses suffering from OIC. Only publications in the English language, with a full text available, were included in the study. We excluded papers that involved pediatric patients, translational studies on healthy subjects with induced constipation, animal studies, use of PAMORAs for non-opioid constipation, non-completed studies, literature reviews, exploratory studies, intensive care unit (ICU) cohorts.

The focus of this review was to define the efficacy and safety of the studied drugs. Hence, we excluded studies that had no such information. Studies without results, incomplete studies, and duplicate studies were also excluded. We used the Rayyan software tool (Rayyan Systems Inc., Cambridge, MA) [28] for the initial title and abstract screening, followed by a full-text screening in a two-stage process by two independent reviewers. Disagreements were resolved by discussion between authors (MR, GV), followed by consulting an external reviewer, if necessary.

\section{Data Extraction}

The two reviewers extracted data independently in a standardized data extraction Excel sheet. Extracted info from each study were study characteristics, year of publication, sample size, age-range and mean, indication and duration for opioids use, type of opioids used, diagnosis of OIC, PAMORA type and dosage, primary outcomes and secondary outcomes, duration of use, effect on OIC, pain scores, side effects, efficacy and use of concomitant laxatives, adverse effect. Any disagreement or queries were resolved by discussion between authors, followed by consulting an external reviewer (MR, GV, AP), if necessary.

\section{Evaluation of the Risk of Bias}

Nonrandomized trials were assessed using the Newcastle-Ottawa Scale [29]. Randomized trials were assessed using the Cochrane risk of bias tool [30]. Bias assessments are detailed in Table 2. 


\begin{tabular}{|c|c|c|c|c|c|c|}
\hline Study & Domain 1 & Domain 2 & Domain 3 & Domain 4 & Domain 5 & Overall risk of bias \\
\hline Webster et al. [31] & High & Low & Low & Low & Low & High \\
\hline Tack et al. [32] & Low & Low & Low & Low & Low & Low \\
\hline Webster et al. [33] & Low & Low & Low & Low & Low & Low \\
\hline Coyne et al. [34] & Low & Low & Low & Low & Low & Low \\
\hline Jansen et al. [35] & Low & Low & Low & Low & Low & Low \\
\hline Webster and Israel [36] & Low & Low & Low & Low & Low & Low \\
\hline Portenoy et al. [37] & High & Low & Low & Low & Low & High \\
\hline Thomas et al. [38] & Low & Low & Low & Low & Low & Low \\
\hline Bull et al. [39] & Low & Low & Low & Low & Low & Low \\
\hline lyer et al. [40] & Low & Low & Low & Low & Low & Low \\
\hline Michna et al. [41] & Low & Low & Low & Low & Low & Low \\
\hline Rauck et al. [42] & Low & Low & Low & Low & Low & Low \\
\hline Webster et al. [43] & High & Low & Low & Low & Low & High \\
\hline Rauck et al. [44] & Low & Low & Low & Low & Low & Low \\
\hline Yuan et al. [45] & Low & Low & Low & Low & Low & Low \\
\hline Chamberlain et al. [46] & Low & Low & Low & Low & Low & Low \\
\hline Lipman et al. [47] & High & Low & Low & Low & Low & High \\
\hline Nalamachu et al. [48] & Low & Low & Low & Low & Low & Low \\
\hline Yuan et al. [49] & Low & Low & Low & Low & Low & Low \\
\hline Wild et al. [50] & Low & Low & Low & Low & Low & Low \\
\hline Katakami et al. [51] & Low & Low & Low & Low & Low & Low \\
\hline Katakami et al. [52] & Low & Low & Low & Low & Low & Low \\
\hline Hale et al. [53] & Low & Low & Low & Low & Low & Low \\
\hline Webster et al. [54] & Low & Low & Low & Low & Low & Low \\
\hline Webster et al. [55] & Low & Low & Low & Low & Low & Low \\
\hline Saito et al. [56] & High & Low & Low & Low & Low & High \\
\hline
\end{tabular}

TABLE 2: RoB 2 [30]: A revised Cochrane risk-of-bias tool for randomized trials. This table demonstrates the risk of bias across included RCTs.

Domain 1: Randomization process

Domain 2: Deviation from intended interventions

Domain 3: Missing outcome data

Domain 4: Measurement of the outcome

Domain 5: Selection of the reported results.

\section{Results}

Our search retrieved 209 trials (130 Embase, 56 PubMed, 34 CT.gov, 18 ICTRP and 1 CINAHL) published from 1996 to 2021; Figure 1). Further screening of articles introduced another 24 papers. After the removal of duplicates, we screened 195 papers. Of them, 5 papers did not have a full text available, and according to the 
inclusion criteria, only 26 studies were found to be eligible for further analysis. The selected studies represented a total of 11,815 patients. We included one study evaluating alvimopan, 14 studies evaluating methylnaltrexone (10 RCTs and 1 post hoc analysis and 3 open-label studies), 4 studies that evaluated naloxegol (two RCTs [31,32], one open-label study [33] and one post-hoc analysis of RCT [34], 7 studies on naldemedine (all RCTs). Two studies looked at cancer pain, 15 at non-cancer pain, 8 studies include both cancer and non-cancer patients, while 1 did not specify.
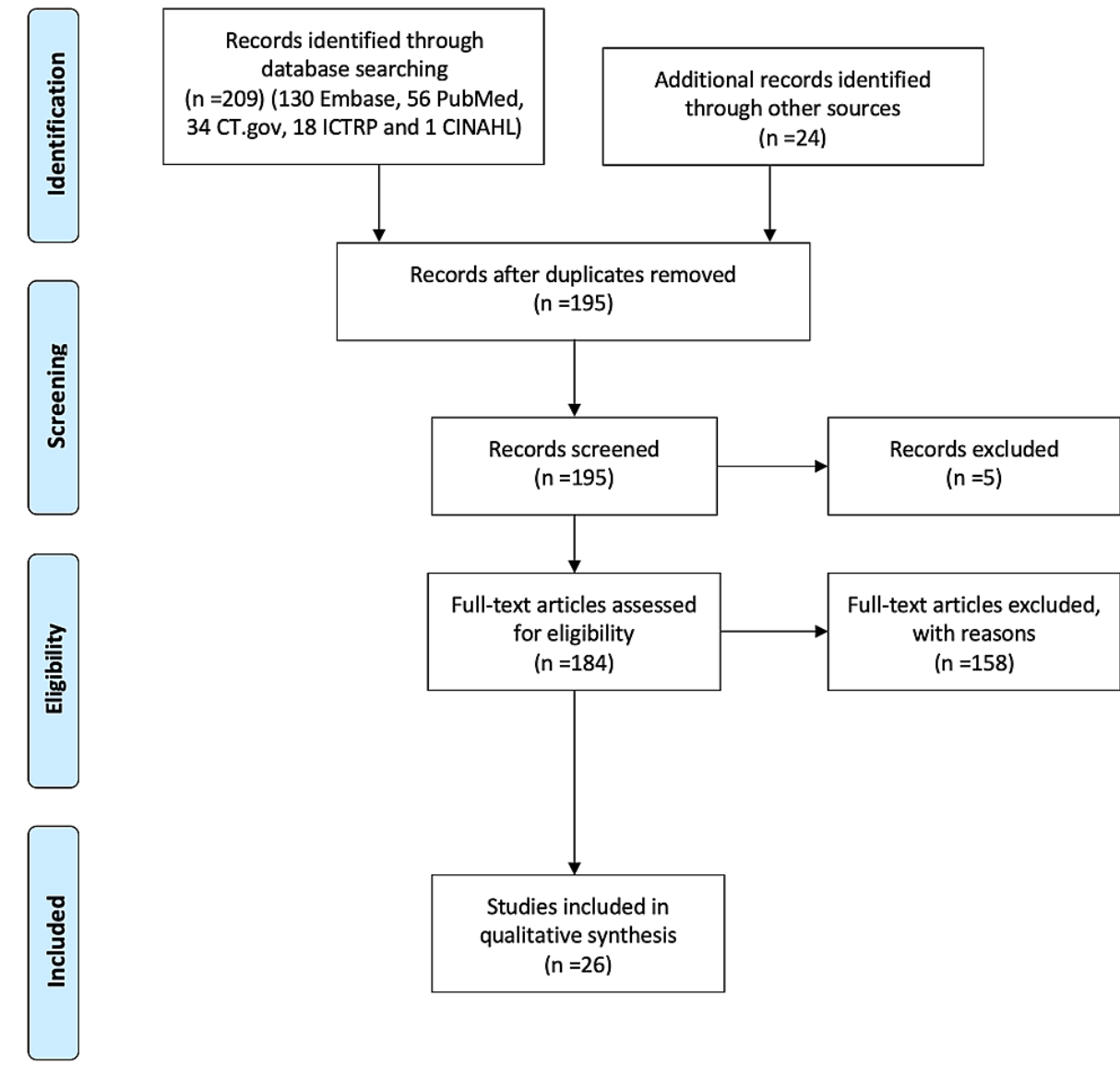

\section{FIGURE 1: PRISMA flow diagram showing literature search and selection of studies in the analysis.}

Although the number of reported cases is high, the heterogeneity of data did not allow an acceptable metaanalysis. Hence, we decided to limit the study to systematically review the selected papers.

\section{Alvimopan}

One study on alvimopan was eligible for this review [35]. This study evaluated a single daily oral dose of 0.5 $\mathrm{mg}$ alvimopan versus $0.5 \mathrm{mg}$ twice daily, versus placebo in non-cancer pain patients with OIC for 12 weeks.

Efficacy: A significantly greater proportion of patients in the alvimopan $0.5 \mathrm{mg}$ twice-daily group showed more than three spontaneous bowel movements (SBMs) per week ( $72 \%$ versus $48 \%, \mathrm{P}<0.001$ ). Moreover, treatment with alvimopan twice daily improved a number of other symptoms compared with placebo and reduced the requirement for rescue laxative use. Alvimopan $0.5 \mathrm{mg}$ once daily produced qualitatively similar but numerically smaller responses than twice-daily treatment. Active treatment did not increase the requirement for opioid medication or in average pain intensity scores [35].

Safety: Over the 12-week treatment period, alvimopan appeared to be well tolerated. There were no statistically significant differences between either dose of alvimopan and placebo over the incidences of treatment-emergent adverse events (TAEs). TAEs affecting the GI system were the most frequently reported ( $22 \%$ in the placebo group, $28 \%$ in the once-daily group and $24 \%$ in the twice-daily group) [35]. Of note, this single study did not identify the significant severe cardiovascular side effects, which led to approval only for large or small bowel resection surgery with primary anastomosis by FDA (Supplemental Material), but not in Europe. 


\section{Cureus}

Fourteen studies were included; mostly RCTs, one post hoc analysis of RCT [36], and three open-label extended (OLE) studies [37-39]. Six studies included non-cancer pain patients [36,40-44], six studies included both cancer and non-cancer [37,39,45-48], one study included patients with advanced illness [38] and one study did not specify its population [49].

Ten studies used methylnaltrexone as subcutaneous (SC) administration (doses of 0,1 mg/kg, $0.15 \mathrm{mg} / \mathrm{kg}, 0.3$ mg/kg, 1 mg, 5 mg, 12 mg, 20 mg) [37-41,43,46-49]. One study used it intravenously (0.2 mg/kg) [45]. Three studies administered it orally (doses of $150 \mathrm{mg}, 300 \mathrm{mg}$ and $450 \mathrm{mg}$ ) [36,42,44]. Two of the latter three studies $[42,44]$ utilized the same group of patients but reported either on efficacy or safety of the drug. The duration of the RCTs ranged from 7 hours to 48 weeks and the OLE studies ranged from three weeks to three months. Two studies included patients already on methadone maintenance program [36,49].

Efficacy: All studies showed efficacy in methylnaltrexone as measured by their primary outcome. Most of the studies measured the percentage of patients with rescue free bowel movements within four hours of the first dose. While two studies measured oral cecal transit time $[45,49]$, one study measured constipation symptoms and pain (PAC-SYM) [40] (Table 3). 


\section{Cureus}

Dose

Methylnaltrexone

$0.15 \mathrm{mg} / \mathrm{kg}$ or 0.3

$\mathrm{mg} / \mathrm{kg}$, vs placebo

Methylnatrexone 1

$\mathrm{mg}, 5 \mathrm{mg}, 12.5 \mathrm{mg}$,

$20 \mathrm{mg}$

Methylnaltrexone

$(0.15 \mathrm{mg} / \mathrm{kg}) \mathrm{vs}$

placebo

Methylnatrexone 8

$\mathrm{mg}$ or $12 \mathrm{mg}$ vs

placebo once daily

Methylnaltrexone 12

mg once daily or

placebo

Methylnatrexone 12

mg once daily,

methylnaltrexone 12 SC

mg alternate days

vs placebo

Methylnatrexone 12

mg once daily

Methylnatrexone $0.15 \mathrm{mg} / \mathrm{kg}$ as a first dose, adjusted to $0.3 \mathrm{mg} / \mathrm{kg}$ or 0.075 $\mathrm{mg} / \mathrm{kg}$ as needed

Methylnatrexone

$0.15 \mathrm{mg} / \mathrm{kg}, 0.3$

$\mathrm{mg} / \mathrm{kg}$ vs. placebo

Methylnatrexone 0.1

$\mathrm{mg} / \mathrm{kg}$ in six

subjects, and 0.3

SC

Not assessing bowel movements

$\mathrm{mg} / \mathrm{kg}$ in six

subjects

Methylnaltrexone

150,300 or $450 \mathrm{mg}$

once daily vs.

placebo

Methylnaltrexone

150,300 or $450 \mathrm{mg}$

once daily vs.

placebo

Methylnatrexone 0.2

$\mathrm{mg} / \mathrm{kg}$
SC

Methylnaltrexone elicited a bowel movement within four hours in $34.1 \%$ of the injections throughout the 48-week treatment period.

Route Bowel movements

SC

The median time to bowel movement response was 0.5 hours in the methylnaltrexone

group and 2.0 hours in the placebo group $(P=0.013)$.

The median time to laxation was $>48$ hours for the $1 \mathrm{mg}$ dose group, compared to 1.26 Portenoy et hours for all patients receiving $\geq 5 \mathrm{mg}$

al. [37]

Thomas et

al. [38]

Bull et al.

[39]

lyer et al.

$58.7 \%$ of patients in the methylnaltrexone once-daily group, $45.3 \%$ in the alternate-day dosing group, and $38.3 \%$ in the placebo group had at least three rescue-free bowel movements per week.

Michna et

al. [41]

Webster et

al. [43]

Lipman et

al. [47]

Author

hamberlain

al. [46]
SC

response usually occurred in a median time of 30 minutes or less.

More than $50 \%$ of patients treated with either methylnaltrexone dose experienced a rescue-free bowel movement within four hours vs. $14.6 \%$ of placebo-treated patients. The largest differences vs. placebo were observed for patients taking methylnaltrexone $0.30 \mathrm{mg} / \mathrm{kg}$ with a noncancer primary diagnosis and for patients taking methylnaltrexone $0.30 \mathrm{mg} / \mathrm{kg}$ maintained on $\geq 150 \mathrm{mg} /$ day baseline morphine equivalent doses.

Nalamachu et al. [48]

Yuan et al. [49]

Webster and

Israel [36] oral methylnaltrexone $300 \mathrm{mg}$ and $450 \mathrm{mg}$. Only the $300 \mathrm{mg}$ dose produced a statistically significant response compared with the placebo

Rauck et al. $450 \mathrm{mg}$; in $8 \%$ of patients in the placebo group.

Yuan et al.

[45]

\section{TABLE 3: Methylnaltrexone efficacy studies.}

SC: subcutaneous, IV: intravenous. 
Subcutaneous route: Three studies administered subcutaneous methylnaltrexone or placebo. The first study included patients with advanced illnesses due to cancer and the results showed a higher response in the active treatment group $(0.15 \mathrm{mg} / \mathrm{kg})$. Also, the median time to response was statistically significant with 0.5 hours in the methylnaltrexone group $(0.15 \mathrm{mg} / \mathrm{kg})$ versus 2 hours in the placebo group [46]. Accordingly, Lipman et al. [47] suggested that the mean response rate for the subcutaneous methylnaltrexone group of $0.15 \mathrm{mg} / \mathrm{kg}$ was $45.3 \%$ and this remained constant through the three-month open-label study (45.5-57.7\%). Similarly, in another study, the mean response rate was $48 \%$ for the $0.15 \mathrm{mg} / \mathrm{kg}$ SC methylnaltrexone group and only $15 \%$ in the placebo group, while this difference between study and placebo groups remained significant after adjustment for baseline opioid dose [38]. Some investigators chose to examine two different subcutaneous doses; $0.15 \mathrm{mg} / \mathrm{kg}$ and $0.30 \mathrm{mg} / \mathrm{kg}$ of methylnaltrexone. Significantly larger proportion of patients in both study groups found the intervention useful $(54.1 \%$ in $0.15 \mathrm{mg} / \mathrm{kg} \mathrm{SC}$ dose, $58.2 \%$ in 0.30 $\mathrm{mg} / \mathrm{kg}$ dose SC, $14,6 \%$ in the placebo $\mathrm{P}<0.001$ ) [48].

Other studies administered a fixed dose of methylnaltrexone rather than by weight. Webster et al. [43] observed a statistically significant increase in mean weekly bowel movements (BM) rate from baseline (mean change $=1.5 \mathrm{BM} / \mathrm{wk}, \mathrm{P}<0.001$ ) in patients on a total SC dose of $12 \mathrm{mg}$ methylnaltrexone once daily during a 48-week period compared to the placebo group. Another study utilized a dose of $12 \mathrm{mg}$ of SC methylnaltrexone that was given either daily or every second day to chronic non-malignant pain patients reporting OIC [41]. Within four hours after the first dose, $34.2 \%$ of patients in both methylnaltrexone groups had bowel movements versus $9.9 \%$ on placebo [41]. In patients with advanced illness and OIC, subcutaneously administered methylnaltrexone doses between 5 and $20 \mathrm{mg}$ induced a laxation response within four hours significantly more often than a dose of $1 \mathrm{mg}$ (50\% versus 10\%) [37]. Interestingly, there was no dose-response relationship above $5 \mathrm{mg}$ per day. Bull et al. [39] also tried to assess if a fixed dose of methylnaltrexone ( $8 \mathrm{mg}$ for under $62 \mathrm{~kg}$ and $12 \mathrm{mg}$ for $\geqslant 62 \mathrm{~kg}$ ) would be as efficacious as the doses based on body weight in patients with advanced illness. The percentage of patients achieving rescue-free bowel movements within four hours after $\geqslant 2$ of the first four doses in the first week was $62.9 \%$ and $9.6 \%$ for methylnaltrexone and placebo groups, respectively, and was statistically significant.

Yuan et al. [49] trialed two different doses of subcutaneous methylnaltrexone plus morphine, $0.1 \mathrm{mg} / \mathrm{kg}$ and $0.3 \mathrm{mg} / \mathrm{kg}$, and found that both dosing regimens reduced the transit times versus the placebo plus morphine. Another finding of this study was that SC methylnaltrexone beyond the advantage of treating OIC, also reduced other unspecified opioid-induced unpleasant subjective symptoms as rated by a 12-item modified opiate adjective checklist.

Iyer et al. [40] studied two dosing regimen schemes for subcutaneous methylnaltrexone and both proved to reduce OIC significantly more than placebo. They were using $12 \mathrm{mg}$ daily or $12 \mathrm{mg}$ every second day, while approximately $60 \%$ of the patients were being treated for lower back pain.

Oral route: A significantly greater percentage of patients in oral methylnaltrexone groups $300 \mathrm{mg} / \mathrm{d}$ (26.4\%, $\mathrm{P}=0.002)$ and $450 \mathrm{mg} / \mathrm{d}(27.4 \%, \mathrm{P}<0.001)$ achieved mean percentage dosing days that resulted in rescue free bowel movements within four hours of dosing compared with placebo (18.2\%). Methylnaltrexone $150 \mathrm{mg}$ also showed improvement compared to placebo (19.9\%) but this improvement was not significant [42].

In patients taking concomitant methadone, a greater percentage of patients treated with oral methylnaltrexone $300 \mathrm{mg}(33.6 \%, \mathrm{P}<0.01)$ or $450 \mathrm{mg}(38.2 \%, \mathrm{P}<0.001)$ achieved the same endpoint as the previous study [42] compared to $15.1 \%$ in the placebo group. In the same post hoc analysis, the improvements with $150 \mathrm{mg}$ (20.0\% of the sample) did not reach statistical significance [36].

Intravenous route: In patients using concomitant methadone, intravenous methylnaltrexone at a dose of $0.365 \mathrm{mg} / \mathrm{kg}$ was compared to placebo. The efficacy of the study medication was both proven by statistically significant improved laxation and reduced oral-cecal transit times, as well as higher patient satisfaction in the methylnaltrexone group [45].

Safety: In general, all studies showed that methylnaltrexone is well tolerated in treating OIC in patients with advanced illness and non-cancer pain. Most of the recorded side effects included abdominal pain, flatulence and diarrhea. One study focused just on safety endpoints, such as TAEs [44]. The most commonly reported adverse event (AEs) in the SC methylnaltrexone studies were mild such as abdominal pain [37-40,43,46-48]. This was also the case in patients treated with oral methylnaltrexone [36,42]. In a study involving multiple doses of oral methylnaltrexone, drug-related AEs occurred in higher percentages in patients treated with higher doses [44].

Serious adverse events associated with methylnaltrexone were reported in the form of extrasystoles [41], syncope [37] and non-cardiac chest pain [42]. They all resolved upon discontinuation. In non-cancer patients on long-term opioids, an OLE study 48-week study showed several major adverse coronary events (cardiac arrest, MI, CVA, sudden death) in patients with underlying CV risk factors [43]. Other serious adverse effects were also reported. These were deemed not to be related to the study drug but associated with underlying disease progression, i.e., progression of neoplasm [38,46-48], death [37-39,47], pneumonia [43]. 
Importantly, pain scores were minimally changed throughout the study compared with baseline in all studies [38-44,46,47]. Additionally, opioid withdrawal symptoms were either none or mild in the methylnaltrexone groups $[38,41,43,46,47]$. Webster et al. [36] found that hyperhidrosis which was deemed related to opioid withdrawal symptoms; was higher in all the oral methylnaltrexone groups compared to none in the placebo group. In subjects with methadone-induced constipation, no opioid withdrawal symptoms were observed with the use of IV methylnaltrexone [45].

Naloxegol

The included papers were two RCTs [31,32], one OLE study [33], and one post-hoc analysis of RCT [34]. Tack et al. [32] randomized 720 non-cancer patients with symptoms of OIC, that were on a stable dose of opioids (Oral Morphine Equivalent (MEQ)> $30 \mathrm{mg} /$ day) for more than two weeks. The patients were given either oral naloxegol (12.5 mg or $25 \mathrm{mg}$ ) or placebo for 12 weeks, while the main conditions treated with opioids were back pain, arthritis, fibromyalgia and joint pain.

Webster et al. [33] reported a multicenter, double-blind RCT which included both cancer and non-cancer patients who were on stable opioid doses for at least two weeks. They randomized 208 patients into three cohorts (oral naloxegol $5 \mathrm{mg}, 25 \mathrm{mg}$ and $50 \mathrm{mg}$ ) or placebo groups. Patients were stratified into a low opioid group (30-100 daily MEQ) and a high opioid group (30-1000 daily MEQ). All laxatives were discontinued apart from Bisacodyl (an organic compound that is used as a stimulant laxative) if SBM had not occurred in a 72 hours period. The study was conducted over four weeks period [33].

Coyne et al. [34] conducted a post hoc analysis of the assessment of efficacy and safety in patients with noncancer-related pain and opioid-induced constipation program for naloxegol (KODIAK No4 and No5) which included 1337 patients. The post hoc analysis was a secondary analysis of pooled data from the above studies to examine the relationship between changes from baseline in quality of life (Patient Assessment of Constipation Quality of Life - PAC-QOL), symptoms (Patients Assessment of Constipation-Symptoms - PACSYM), stool hardness (Bristol Stool Scale) and rectal straining. The patients had received a daily dose of oral 12.5 or $25 \mathrm{mg}$ of naloxegol or placebo [34].

The fourth is an OLE study, which recruited new patients without prior naloxegol treatment $(\mathrm{n}=760)$ or rollover patients from KODIAK No4 and No5 $(n=84)$. This open-label study assessed the long-term safety and tolerability of naloxegol over the course of 52 weeks. Additionally, non-cancer patients taking 30-1000 MEQ per day for more than four weeks were randomized 2:1 to receive naloxegol $25 \mathrm{mg}$ /day or usual care (investigator-chosen laxative regimen) treatment for OIC [31].

Efficacy: Naloxegol proved to be more effective than placebo in all of the studies (Table 4). In one study, the number of patients having three or more SBM per week was greater in both the naloxegol groups ( $25 \mathrm{mg}$, $54.4 \% ; 12.5 \mathrm{mg}, 39.2 \%$ ) compared to placebo (27.2\%). SBM was defined as a bowel movement that occurred without the use of rescue laxatives within the previous 24 hours. Also, the median time to first post-dose SBM were 7.6, 19.2 and 41.1 hours for the naloxegol $25 \mathrm{mg}$, naloxegol $12.5 \mathrm{mg}$ and placebo groups, respectively, indicating significantly greater efficacy of naloxegol $25 \mathrm{mg}$ [32]. 


\section{Cureus}

Dose

Bowel movements

Naloxegol

$25 \mathrm{mg} / \mathrm{d}$

vs usual

care

Naloxegol

$25 \mathrm{mg}$,

$12.5 \mathrm{mg}$

vs

placebo

Naloxegol

$5 \mathrm{mg}, 25$

$\mathrm{mg}, 50$

mg once

daily or

placebo

Naloxegol

$25 \mathrm{mg}$,

$12.5 \mathrm{mg}$

vs

placebo placebo
Did not assess spontaneous bowel movements

Author

Webster

et al.

[31]

Median time to bowel movement response 7.6 hours for naloxegol $25 \mathrm{mg} 19.2$ hours for $12.5 \mathrm{mg} 41.1$ hours for Tack et
placebo

(1)

At week 1, the median change from baseline in spontaneous bowel movements per week: In the 5-mg dose group; no statistical difference versus placebo (1.5 vs 1.2) In the $25 \mathrm{mg}$ dose group; a statistically significantly greater change from baseline versus the placebo (2.9 vs 1.0$)$. In the $50-\mathrm{mg}$ dose group, a statistically significantly greater change from baseline versus the placebo (3.3 vs 0.5$)$. At weeks $2-4$, the median change from baseline in spontaneous bowel movements per week: For the $50 \mathrm{mg}$ dose group: was statistically significantly greater vs placebo at all time points during weeks 2 , 3, and 4 . For $25 \mathrm{mg}$ dose group: was statistically significantly greater vs placebo at all time points except week 2

\section{Webster} et al.

TABLE 4: Naloxegol efficacy.

Webster et al. [33] reported the median change in SBMs per week from baseline to the end of the first week. This was statistically significant in the $25 \mathrm{mg}$ and $50 \mathrm{mg}$ naloxegol groups; the increase in SBMs was maintained over four weeks for naloxegol $25 \mathrm{mg}$ and $50 \mathrm{mg}$ versus placebo and was statistically significant in both groups. Additionally, the median time to the first laxation was significantly shorter with naloxegol than placebo in the 25 -mg cohort (6.6 vs 48.6 hours) and 50-mg cohort ( 2.9 vs 44.9 hours), but not statistically different in the 5 -mg cohort (6.2 vs 28.2 hours; $\mathrm{p}=0.64$ ).

Tack et al. [32] analyzed the 12-week response rates in the laxative inadequate responders (LIR) group. Patients were classified as LIR if they reported using laxatives for a minimum of four days within two weeks and had continuous stool symptom ratings of moderate, severe or very severe (in response to one or more of the four stool symptom domain questions). SBM response rates and symptoms in the LIR population were significantly higher in both the naloxegol $25 \mathrm{mg}$ and $12.5 \mathrm{mg}$ versus placebo.

Patient Assessment of Constipation - Symptoms (PAC-SYM), Patient Assessment of Constipation - Quality of Life (PAC- QoL), and Short-Form Health Survey (SF-36) scores were also assessed by the studies. Patients treated with $25 \mathrm{mg}$ naloxegol reported lower median total scores on the patient-reported PAC-QoL questionnaire than patients taking a placebo. This group also reported statistically significant improvement in SF-36 scale scores for physical functioning, mental health, social functioning and vitality at various time points during double-blind treatment compared with patients receiving placebo, whereas differences between the $5 \mathrm{mg}$ and $50 \mathrm{mg}$ dose groups and placebo were not significant [33]. In the study of Tack et al. [32], changes from baseline in severity of constipation symptoms as measured by PAC-SYM scores for rectal and stool symptoms were greater for both naloxegol $25 \mathrm{mg}$ and naloxegol $50 \mathrm{mg}$ groups compared with placebo at week 12. PAC-QOL changes from baseline in the satisfaction domain to week 12 were also greater in both naloxegol groups compared to placebo; however, for all other domains (physical discomfort, psychosocial discomfort, worries and concerns) were comparable in both study and placebo groups [32].

Safety and tolerability: In these studies, the type, number and frequency of AEs were assessed. Changes from baseline of MEQ dose, Numeric Rating Scale (NRS) pain score, modified Himmelsbach Opioid Withdrawal Score (mHOWS) and Clinical Opiate Withdrawal Scale (COWS) were also assessed [57]. The mHOWS rates yawning, lacrimation, rhinorrhea, perspiration, tremor, mydriasis, piloerection and restlessness on a scale from 0 (none) to 3 (severe). A greater incidence of overall AEs was reported in the naloxegol 25-mg group (63.1\%) compared with the naloxegol $12.5-\mathrm{mg}$ (50.6\%) or placebo (50.0\%) groups resulting in a higher frequency of discontinuation of study drug [32]. The most common AEs reported in the naloxegol group were abdominal pain, diarrhea and nausea [32]. Flatulence, upper abdominal pain and hyperhidrosis were reported more frequently in the naloxegol $25 \mathrm{mg}$ group, versus the naloxegol 12.5-mg or placebo groups [32]. However, Webster et al. [33] reported that there were no major differences in the frequency or type of 
reported treatment-emergent adverse events (TEAEs) compared with those receiving placebo in patients receiving $5 \mathrm{mg}$ or $25 \mathrm{mg}$ of naloxegol. While most AEs at 5 and $25 \mathrm{mg} /$ day were mild and transient, a difference was noted at the $50 \mathrm{mg}$ cohort where the incidence of TEAEs was higher compared to placebo as was the severity. Accordingly, the most frequently reported TEAEs were GI complaints and included abdominal pain, diarrhea and nausea [33]. A study that compared usual care with naloxegol, stated that the incidence of serious AEs was similar between groups (naloxegol $25 \mathrm{mg}, 9.6 \%$ and usual care, 11.1\%), the treatment-emergent AEs occurring more frequently for naloxegol versus usual care were abdominal pain ( $17.8 \%$ vs. $3.3 \%)$, diarrhea (12.9\% vs. $5.9 \%$ ), nausea ( $9.4 \%$ vs. $4.1 \%)$, headache $(9.0 \%$ vs. $4.8 \%$ ), flatulence (6.9\% vs. $1.1 \%)$ and upper abdominal pain (5.1\% vs. $1.1 \%)$. [31].

During the study period, the proportions of patients with increases from baseline in opioid dose, NRS pain score, and mHOWS were similar among treatment groups [32]. Also, Webster et al. [33] stated that there were no significant changes from baseline for mean daily opioid dose for the 25- or 50-mg cohort. Mean NRS scores remained consistent from baseline to week 4 of double-blind treatment for all three cohorts, and no differences vs placebo were observed [33]. Additionally, significant differences in median Clinical Opiate Withdrawal Scale (COWS) total score were observed between placebo and naloxegol in the 5- and 25-mg cohorts. However, a difference was observed in median COWS total score in the 50-mg cohort at day 1 of week 1 compared to placebo ( 1.0 vs. $0.0 ; \mathrm{P}=0.0069$ ) [33]. In the same study, pain scores and mean daily opioid doses remained stable throughout the study period, with a mean change from baseline of $<0.4$ on the $0-10$ NRS pain scale, for the active treatment group. In patients with noncancer pain and OIC, naloxegol $25 \mathrm{mg}$ was generally safe and well-tolerated over 52 weeks [31].

Naldemedine

Seven RCTs were included, and all of them compared naldemedine to placebo. The age of all subjects was over 18 years, but one study only included a subgroup aged 65-80 years [51]. Most of them studied the use of naldemedine for OIC in non-cancer patients, but two studies included only cancer pain patients [51,52]. Patients with OIC on a stable dose of opioids were included, while the duration of time where patients used opioids ranged from 2 weeks to 4 weeks prior to the study. The studies used oral naldemedine, with most using $0.2 \mathrm{mg}$ once daily; two papers studied three different doses $(0.1 \mathrm{mg}, 0.2 \mathrm{mg}$ and $0.4 \mathrm{mg})[51,52]$. The duration of studies ranged between 2 weeks and 52 weeks, while the OLE study extended to 12 weeks.

Efficacy: All studies reported positive efficacy of one daily dose of oral naldemedine compared to placebo in treating patients with OIC (Table 5). The doses that were evaluated were $0.1 \mathrm{mg}, 0.3 \mathrm{mg}$ and $0.4 \mathrm{mg}$. Hale et al. [53] reported two RCTs (COMPOSE 1 and 2), which randomly assigned patients to receive $0.2 \mathrm{mg}$ oral naldemedine or placebo. The proportion of responders in both trials was significantly higher in naldemedine group than in the placebo group; $47.6 \%$ compared to $34.6 \%$ ( $\mathrm{p}=0.002$ ) in COMPOSE 1 , and $52.5 \%$ vs $33.6 \%$ $(\mathrm{p}<0.0001)$ in COMPOSE 2. A COMPOSE-4 study, utilizing the same oral dose of the study medication, which included only cancer patients, also revealed that the proportion of responders was higher in the naldemedine group (71.1\%) vs placebo (34.4\%), $\mathrm{P}<0.001$ [55]. In the latter study, a greater change from baseline was observed with naldemedine than with placebo in the frequency of SBMs/week (5.16 v 1.54 ; $\mathrm{p}<0.0001)$ [52]. 


\section{Cureus}

\section{Dose}

Bowel movements

Naldemedine

$0.2 \mathrm{mg}$ vs

placebo

once daily

Naldemedine

$0.1 \mathrm{mg}, 0.2$

$\mathrm{mg}, 0.4 \mathrm{mg}$

once daily vs

placebo

Naldemedine

$0.2 \mathrm{mg}$ once

daily vs

placebo

Naldemedine

$0.2 \mathrm{mg}$ vs

placebo

Naldemedine

$0.1 \mathrm{mg}, 0.2$

$\mathrm{mg}$, or 0.4

mg once

daily vs

placebo

Naldemedine

$0.2 \mathrm{mg}$ once

daily vs

placebo

Naldemedine

$0.2 \mathrm{mg}$ once

daily
Did not assess bowel movements

Author

Wild et

al. [50]

Change in spontaneous bowel movements frequency (primary endpoint) was higher with all naldemedine doses versus placebo ( $p<0.05$ for all comparisons), as were spontaneous bowel movements responder rates and change in complete spontaneous bowel movements frequency. Change in spontaneous bowel movements frequency without straining was significantly improved with naldemedine 0.2 and 0.4 (but not $0.1) \mathrm{mg}$ versus placebo (at least $p<0.05$ )

The proportion of spontaneous bowel movements responders was significantly greater with naldemedine than with placebo ( $71.1 \%$ vs 34.4$)$. A greater change from baseline was observed with naldemedine than with placebo in the frequency of spontaneous bowel movements/week (5.16 vs $1.54 ; p<0.0001)$, spontaneous bowel movements with complete bowel evacuation/week ( 2.76 vs $0.71 ; p<0.0001)$, and spontaneous bowel movements without straining/week.

Not the primary endpoint. Greater increases were observed in the mean frequency of spontaneous bowel movements per week in the naldemedine group than in the placebo group.

Katakami

et al. [51]

Weekly spontaneous bowel movements frequency was significantly higher with naldemedine $0.2 \mathrm{mg}$

Webster (3.37, $\mathrm{p}=0.0014)$ and $0.4 \mathrm{mg}(3.64, \mathrm{p}=0.0003)$, but not with $0.1 \mathrm{mg}(1.98, \mathrm{p}=0.3504)$, vs placebo (1.42).

et al. [54]

There was a significant and sustained increase from baseline in the frequency of bowel movements with naldemedine vs placebo throughout the 52-week treatment period.

Webster

et al. [55]

Saito et

Did not assess bowel movements

al. [56]

TABLE 5: Naldemedine efficacy.

The beneficial effect of naldemedine on SBM frequency was also supported by a further study [54]. In this, three different doses of oral naldemedine were evaluated $(0.1 \mathrm{mg}, 0.2 \mathrm{mg}$ and $0.4 \mathrm{mg})$. Although both $0.2 \mathrm{mg}$ and $0.4 \mathrm{mg}$ showed to have a statistically significant effect on weekly SBM versus placebo, the authors concluded that the dose of $0.2 \mathrm{mg}$ is the optimal dose. The $0.1 \mathrm{mg}$ oral dose failed to have a significant change versus placebo [54]. This observation was confirmed by Katakami et al. [51] who trialed the same doses.

Safety: Naldemedine was generally well tolerated in terms of potential adverse effects. One study evaluated the safety and efficacy of naldemedine for up to 12 weeks in a subgroup of patients aged over 65 years from three trials (COMPOSE-1, COMPOSE-2 and COMPOSE-3) [50]. In these studies, the incidence of TEAEs in the naldemedine group (45.9\%) was comparable to that in patients receiving placebo (51.6\%). The incidence of gastrointestinal system side effects in the naldemedine group (20.2\%) was also comparable to that in patients receiving a placebo (16.1\%). The incidence of opioid withdrawal in the naldemedine group was $1.1 \%$.

COMPOSE 4 and 5 also assessed the TEAEs (the severity of a TEAE was graded as mild, moderate or severe on the basis of Common Terminology Criteria for Adverse Events, the impact of the TEAE on the daily activities and clinical status of the patient) as well as opioid withdrawal symptoms (assessed with the clinician-administered COWS scoring method) [52]. GI disorders were the most frequently reported TEAE in both COMPOSE 4 and 5 studies, with diarrhea being the most common (COMPOSE-4: naldemedine, 19.6\% vs placebo, 7.3\%; COMPOSE-5: naldemedine, 18.3\% (24 of 131 patients). Vomiting, decreased appetite, pyrexia and abnormal hepatic function test also were attributed to naldemedine use. In COMPOSE4, TEAEs rate was $44.3 \%$ versus the placebo's $26 \%, \mathrm{P}=0.01$, while in COMPOSE-5, $80.2 \%$ of the patients reported TEAEs. Naldemedine was not associated with signs or symptoms of opioid withdrawal and had no 


\section{Cureus}

notable impact on opioid-mediated analgesia [52].

Webster et al. [55] studied the long-term safety of naldemedine in the chronic non-cancer population for 52 weeks. TEAEs (naldemedine, $68.4 \%$ vs placebo, $72.1 \%$ ) and TEAEs leading to study discontinuation (6.3\% vs $5.8 \%$ ) were reported for similar proportions of patients. Diarrhea was reported more frequently with naldemedine (11.0\%) vs placebo (5.3\%). There were no meaningful differences between groups in opioid withdrawal or pain intensity. Saito et al. [56] published COMPOSE 6 and 7 and reported that the most frequent side effects were nasopharyngitis and diarrhea, but were mostly mild or moderate in severity. An increase in pain intensity or opioid withdrawal were not observed.

\section{Discussion}

All the PAMORAs are efficacious drugs for the treatment of OIC (Table 6). Naldemedine is the PAMORA able to produce the highest number of SBM (Figure 2). It is important to remember that a minimum of three SBM per week is one of the criteria of the Roma IV diagnostic tool for OIC [23]. Methylnaltrexone has the most rapid onset, also when administered orally (Figure 3). It is obvious that alvimopan has a very restricted postoperative use after abdominal surgery and has important adverse effects to consider. Methylnaltrexone, naldemedine and naloxegol have all been available for a prolonged period of time, without serious side effects or complications. Methylnaltrexone can be used for up to four months and has FDA approval for both cancer and non-cancer pain. It is available in both oral and subcutaneous forms. This makes drugs advantageous in some situations such as palliative care; however, the restrictions regarding renal and hepatic impairment, which are common in those patients, impose important limitations. Naldemedine and naloxegol are approved in several countries. Both drugs are not recommended in severe hepatic impairment, but naldemedine has no restrictions in patients with renal impairment making this drug very useful.

\begin{tabular}{|c|c|c|c|}
\hline Dose & Route & Bowel movements & Authors \\
\hline $\begin{array}{l}\text { Almivopan } 0.5 \\
\text { mg twice daily or } \\
\text { placebo }\end{array}$ & Oral & $\geq 3$ spontaneous bowel movements per week with no laxative use 24 hours before & $\begin{array}{l}\text { Jansen et al. } \\
\text { [35] }\end{array}$ \\
\hline $\begin{array}{l}\text { Methylnatrexone } \\
1 \mathrm{mg}, 5 \mathrm{mg}, 12.5 \\
\mathrm{mg}, 20 \mathrm{mg}\end{array}$ & SC & $\begin{array}{l}\text { The median time to laxation was } 1.26 \text { hours for all patients receiving } \geq 5 \mathrm{mg} \text { versus }>48 \\
\text { hours for the } 1 \mathrm{mg} \text { dose group }\end{array}$ & $\begin{array}{l}\text { Portenoy et } \\
\text { al. [37] }\end{array}$ \\
\hline $\begin{array}{l}\text { Methylnaltrexone } \\
0.15 \mathrm{mg} / \mathrm{kg} \text { or } \\
\text { placebo }\end{array}$ & SC & $\begin{array}{l}\text { After the first dose: the median time to bowel movement response was four hours in } 48 \% \\
\text { in the methylnaltrexone group versus } 15 \% \text { in the placebo }\end{array}$ & $\begin{array}{l}\text { Thomas et } \\
\text { al. [38] }\end{array}$ \\
\hline $\begin{array}{l}\text { Methylnatrexone } \\
8 \mathrm{mg} \text { or } 12 \mathrm{mg} \text { or } \\
\text { placebo once } \\
\text { daily }\end{array}$ & SC & $\begin{array}{l}\text { After } \geq 2 \text { doses: median time to bowel movement response was four hours in } 62.9 \% \text { in the } \\
\text { methylnaltrexone group versus } 9.6 \% \text { in the placebo }\end{array}$ & $\begin{array}{l}\text { Bull et al. } \\
\text { [39] }\end{array}$ \\
\hline $\begin{array}{l}\text { Methylnatrexone } \\
12 \mathrm{mg} \text { once } \\
\text { daily, or } 12 \mathrm{mg} \\
\text { alternate days or } \\
\text { placebo }\end{array}$ & SC & $\begin{array}{l}\geq 3 \text { spontaneous bowel movements per week with no laxative use } 24 \text { hours betore: } 58.1 \% \\
\text { of patients in the methylnaltrexone once-daily group } 45.3 \% \text { in the alternate-day dosing } \\
\text { group } 38.3 \% \text { in the placebo group }\end{array}$ & $\begin{array}{l}\text { Michna et } \\
\text { al. [41] }\end{array}$ \\
\hline $\begin{array}{l}\text { Methylnatrexone } \\
12 \text { mg once daily }\end{array}$ & SC & $\begin{array}{l}\text { Median time to bowel movement response was four hours in } 34.1 \% \text { of the injections } \\
\text { throughout the } 48 \text {-week treatment period }\end{array}$ & $\begin{array}{l}\text { Webster et } \\
\text { al. [43] }\end{array}$ \\
\hline $\begin{array}{l}\text { Methylnaltrexone } \\
0.15 \mathrm{mg} / \mathrm{kg} \text { or } \\
0.3 \mathrm{mg} / \mathrm{kg} \text { or } \\
\text { placebo }\end{array}$ & SC & $\begin{array}{l}\text { Median time to bowel movement response } 0.5 \text { hours in the methylnaltrexone group versus } \\
2.0 \text { hours in the placebo group }\end{array}$ & $\begin{array}{l}\text { Chamberlain } \\
\text { et al. [46] }\end{array}$ \\
\hline $\begin{array}{l}\text { Methylnatrexone } \\
0.15 \mathrm{mg} / \mathrm{kg} \text { as a } \\
\text { first dose, } \\
\text { adjusted to } 0.3 \\
\mathrm{mg} / \mathrm{kg} \text { or } 0.075 \\
\mathrm{mg} / \mathrm{kg} \text { as needed }\end{array}$ & $\mathrm{SC}$ & Median time to bowel movement response 0.5 hours & $\begin{array}{l}\text { Lipman et } \\
\text { al. [47] }\end{array}$ \\
\hline $\begin{array}{l}\text { Methylnatrexone } \\
0.15 \mathrm{mg} / \mathrm{kg}, 0.3 \\
\mathrm{mg} / \mathrm{kg} \text { or } \\
\text { placebo }\end{array}$ & SC & $\begin{array}{l}\text { Median time to bowel movement response was four hours } \geq 50 \% \text { in patients receiving } \\
\text { either methylnaltrexone dose versus } 14.6 \% \text { of placebo-treated patients. The largest } \\
\text { differences vs. placebo were observed for patients taking methylnaltrexone } 0.30 \mathrm{mg} / \mathrm{kg} \\
\text { with a noncancer primary diagnosis and for patients taking methylnaltrexone } 0.30 \mathrm{mg} / \mathrm{kg}\end{array}$ & $\begin{array}{l}\text { Nalamachu } \\
\text { et al. [48] }\end{array}$ \\
\hline
\end{tabular}




\section{Cureus}

Methylnaltrexone $150,300,450 \mathrm{mg}$ once daily or placebo

Methylnaltrexone 150,300 , or 450 mg or placebo once daily

Naloxegol 25 $\mathrm{mg}, 12.5 \mathrm{mg}$ or placebo

Naloxegol 5, 25, $50 \mathrm{mg}$ once daily Oral or placebo

Naldemedine 0.1 mg, 0.2 mg, 0.4 mg once daily or placebo

Naldemedine 0.2 mg once daily or Oral placebo

Naldemedine 0.2 mg or placebo

Naldemedine 0.1 $\mathrm{mg}, 0.2 \mathrm{mg}$, or $0.4 \mathrm{mg}$ once daily or placebo

Naldemedine 0.2 mg once daily or placebo Oral maintained on $\geq 150 \mathrm{mg} /$ day baseline morphine equivalent doses

Median time to bowel movement response was shorter for patients treated with both oral methylnaltrexone $300 \mathrm{mg}$ and $450 \mathrm{mg}$. Only the $300 \mathrm{mg}$ dose produced a statistically significant response compared with the placebo.

Webster et al. [36]

Median time to bowel movement response was four hours: in $25.4 \%$ of patients receiving methylnaltrexone $300 \mathrm{mg}$. In $23.5 \%$ of patients receiving methylnaltrexone $450 \mathrm{mg}$. In $8 \%$ of patients in the placebo group.

Rauck et al. [42]

Median time to bowel movement response 7.6 hours for naloxegol $25 \mathrm{mg} 19.2$ hours for $12.5 \mathrm{mg} 41.1$ hours for placebo

Tack et al.

At week 1, the median change from baseline in spontaneous bowel movements per week. In the 5-mg dose group, no statistical difference versus placebo (1.5 vs 1.2$)$. In the $25 \mathrm{mg}$ dose group, a statistically significantly greater change from baseline versus the placebo (2.9 vs 1.0). In the $50 \mathrm{mg}$ dose group, a statistically significantly greater change from baseline versus the placebo (3.3 vs 0.5 ). At weeks $2-4$, the median change from baseline in spontaneous bowel movements per week. For the $50 \mathrm{mg}$ dose group: was statistically significantly greater vs placebo at all time points during weeks 2 , 3, and 4 . For $25 \mathrm{mg}$ dose group: was statistically significantly greater vs placebo at all time points except week 2 .

Oral Spontaneous bowel movements frequency higher (and statistically significant) with all naldemedine doses versus placebo

Katakami et al. [51]

Spontaneous bowel movements per week were: 5.16 in naldemedine versus 1.54 in the placebo group

Katakami et al. [52]

Mean frequency of spontaneous bowel movements per week was statistically significant Oral in the naldemedine group: COMPOSE-1: 2.58 vs 1.57 in placebo COMPOSE-2: 2.77 vs 1.62 in the placebo

Hale et al.

Spontaneous bowel movements frequency per week: was significantly higher with Oral naldemedine $0.2 \mathrm{mg}(3.37, \mathrm{P}=0.0014)$ and $0.4 \mathrm{mg}(3.64, \mathrm{P}=0.0003)$ but not with $0.1 \mathrm{mg}$ (1.98, $\mathrm{P}=0.3504)$, vs placebo (1.42)

Webster et al. [54]

Spontaneous bowel movements frequency per week: a significant and sustained increase from baseline with naldemedine vs placebo throughout the 52-week treatment period
Webster et al. [55]

\section{TABLE 6: Bowel movements after PAMORAs administration.}

SC: subcutaneous; PAMORAs: Peripherally acting $\mu$-opioid receptor antagonists. 


\section{Cureus}

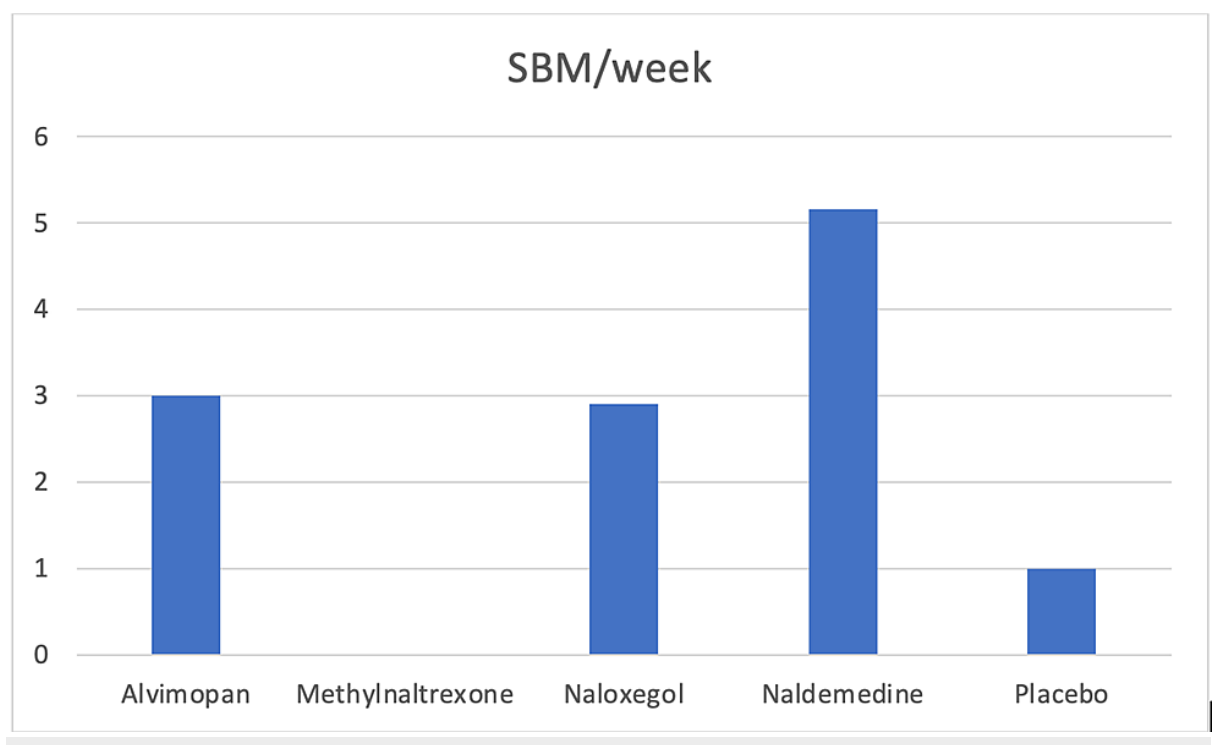

FIGURE 2: Spontaneous bowel movements per week after some PAMORAs administration.

Data deriving from different publications: Almivopan (0.5 mg 2/day), Jansen et al. [35]; Naloxegol (25 mg): Webster et al. [33]; Naldemedine (0.2 mg 1/day), Katakami et al. [51,52]; Methylnaltrexone: SBM are reported just for their speed of appearance, not for the quantity per week.

PAMORAs: Peripherally acting $\mu$-opioid receptor antagonists.

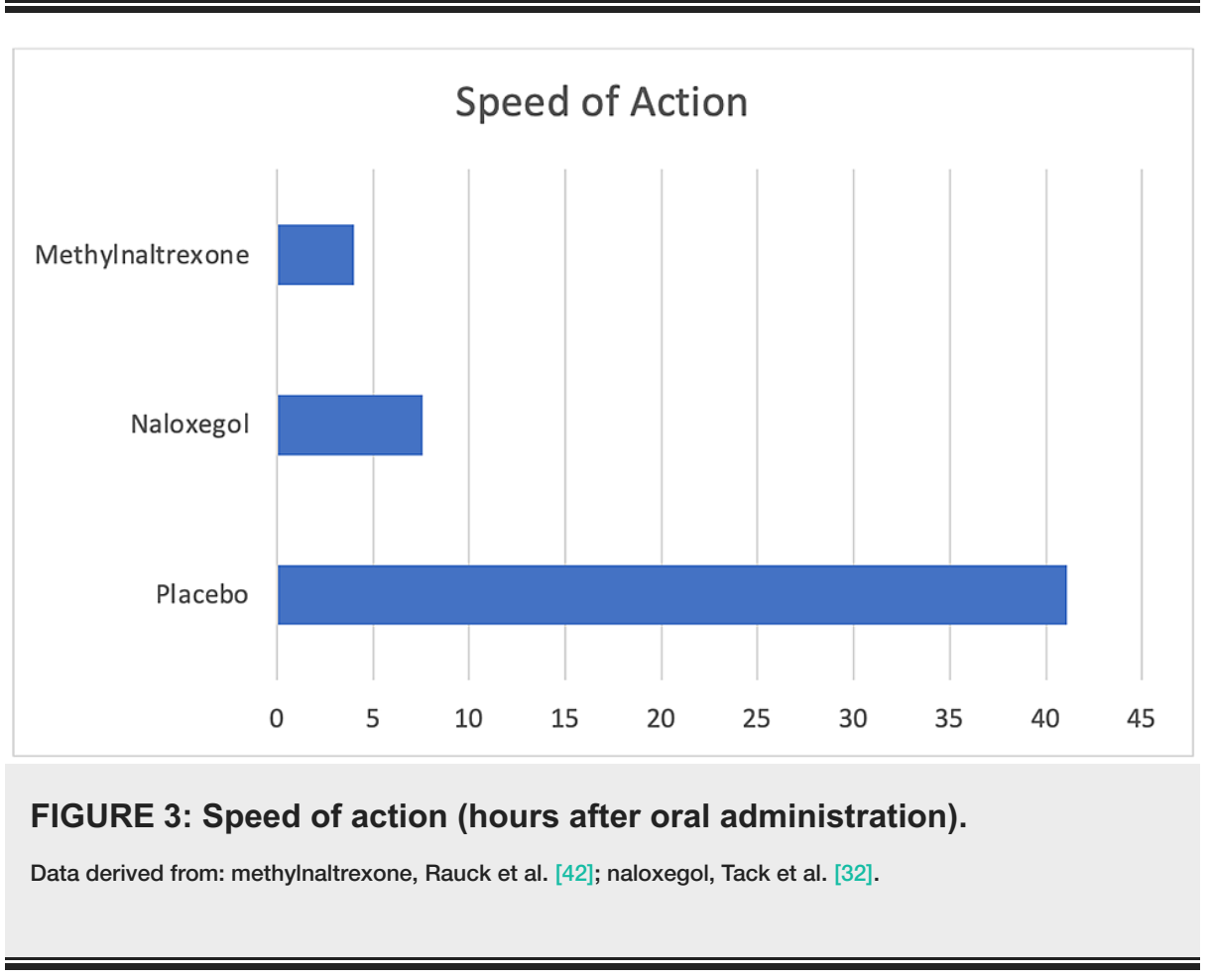

The only study on alvimopan in OIC showed that an oral dose of $0.5 \mathrm{mg}$ twice daily was effective, and it was in general well tolerated [35]. Alvimopan was approved as a generic drug by FDA, on December 20, 2019, "to accelerate the time to upper and lower gastrointestinal recovery following partial large or small bowel resection surgery with primary anastomosis" [58]. Hence, for the treatment of postoperative ileus after upper and lower gastrointestinal (GI) surgery [59]. The recommended dose is $12 \mathrm{mg}$ administered 30 minutes to 5 hours prior to surgery followed by $12 \mathrm{mg}$ twice daily for up to seven days for a maximum of 15 doses. After the study of Jansen et al. [35], FDA warns of a possible higher risk of myocardial infarctions with long-term use, although a causal relationship with alvimopan has not been established. A short-term treatment only is recommended, making alvimopan an unsuitable agent for patients on long-term opioids [60,61]. This drug could possibly serve as a part of Enhanced Recovery After Surgery protocols (ERAS) [62]. Further studies 
have to be undertaken in order to establish a definitive conclusion regarding cost-effectiveness, safety and effect on pain scores, as the existing results are inconclusive $[63,64]$.

Methylnaltrexone, in the studies that were included in our results, was actually administered both subcutaneously, intravenously and orally. Table 3 summarizes the findings of each study regarding bowel movements and dosing. Importantly, in studies involving multiple doses of methylnaltrexone, drug-related AEs occurred in higher percentages in patients treated with higher doses (Table 7) and it is worth noting that higher doses did not relate with a better response on some occasions. A metanalysis on methylnaltrexone concluded that $0.15 \mathrm{mg} / \mathrm{kg}$ and $0.30 \mathrm{mg} / \mathrm{kg}$ doses every other day, as well as a dose of $12 \mathrm{mg} / \mathrm{day}$, were effective [65]. A retrospective analysis including data from the past ten years reports that methylnaltrexone led to a shorter hospital stay and no differences among pain scores or opioid consumption [66]. However, there are some restrictions in dosing of palliative care patients, and also those with renal and hepatic impairment [59]. Moreover, there are warning on potential intestinal perforation due to SC methylnaltrexone administration $[67,68]$.

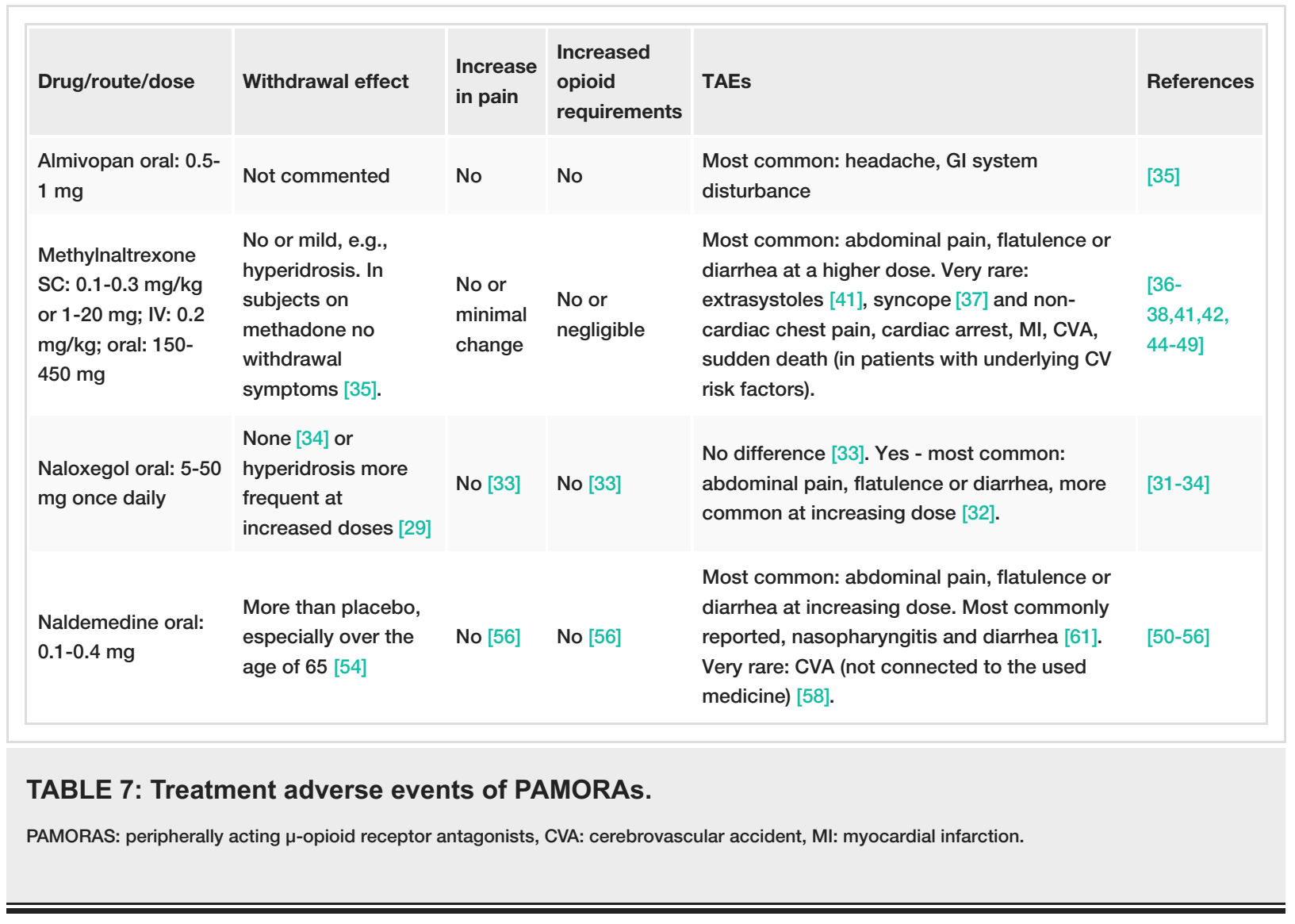

Naloxegol $12.5 \mathrm{mg}, 25 \mathrm{mg}$ and $50 \mathrm{mg}$ orally proved to be more effective than placebo in all the studies, but not at the dose of $5 \mathrm{mg}$. The results among the effective doses were comparable as well. In general, a greater incidence of overall AEs such as diarrhea, nausea, headache, flatulence, upper abdominal pain, and hyperhidrosis was reported in higher doses by some studies, whereas other studies did not find any differences among $5 \mathrm{mg}$ and $25 \mathrm{mg}$, but only between $25 \mathrm{mg}$ and 50mg, where the incidence and severity of AEs were significantly higher in the group receiving the higher dose [33]. This is also supported by a previous review where it is stated that the recommended dosage of naloxegol is $25 \mathrm{mg}$ once daily in the morning before food intake, while under certain circumstances, the recommended dosage is $12.5 \mathrm{mg} / \mathrm{day}$ (e.g., tolerability issues/ drug interactions, or as a starting dosage in patients with moderate, severe or end-stage renal impairment) [69]. Finally, in the summary of product characteristics published by the European Medicines Agency (EMA) for naloxegol, the recommended dose is $25 \mathrm{mg}$ once daily [70]. When naloxegol therapy is initiated, it is recommended that all currently used maintenance laxative therapy should be halted, until the clinical effect of naloxegol is determined. No dose adjustment is recommended based on age, but the starting dose is $12.5 \mathrm{mg}$ in severe renal insufficiency. Use in patients with severe hepatic impairment is not recommended. If side effects impacting tolerability occur, naloxegol should be discontinued or the dose to be decreased [70].

Effects of oral naldemedine $0.1 \mathrm{mg}$ were not significantly different compared to placebo. Results obtained with $0.2 \mathrm{mg}$ and $0.4 \mathrm{mg}$ doses were significantly better in all the studies using these dosages. Additionally, a metanalysis showed that the dose of naldemedine $0.2 \mathrm{mg}$ daily provided a significant reduction of symptoms in patients with OIC and was generally well tolerated [71]. Another meta-analysis concluded that there was 
a significant difference between the naldemedine $0.1 \mathrm{mg}$ and $0.2 \mathrm{mg}$ group for treatment efficacy, but there were no differences between $0.2 \mathrm{mg}$ and $0.4 \mathrm{mg}$ [72]. Regarding the adverse effects, some studies showed that there is no difference between the studied drug and placebo. Others showed a higher frequency of AEs and more discontinuation in the treatment group. Also, they showed that the incidence of serious adverse effects (AEs) was higher with naldemedine than with placebo, especially in the cancer patient subgroup, but they were mild to moderate and well-tolerated during treatment [72]. A study that included two RCTs confirmed that naldemedine, at a dose of $0.2 \mathrm{mg}$, benefits patients with OIC and cancer irrespective of baseline characteristics [73]. Also, this dose did not appear to affect analgesia or produce withdrawal symptoms. Pharmacokinetic assessments indicate that dose adjustments for naldemedine are not necessary for subjects with any degree of renal impairment $[74,75]$ or for subjects with mild or moderate hepatic impairment [74], which makes the drug a very useful agent for OIC in a relatively large group of patients treated with opioids.

Finally, naloxegol is not recommended when used with CYP3A4 inhibitors and inducers, while naldemedine can be used with the indications to monitor/decrease the doses if needed [76]. Considering what is reported above, the choice of the right PAMORA depends on many clinical components, but there are clear rules that should be followed [77].

\section{Limitations}

This study has several limitations. The most important is that a credible meta-analysis to compare the results obtained with the different PAMORAs cannot be done due to the heterogeneity between studies. The available data for the four PAMORAs are very different and the comparative analysis of some of them is very difficult. As an example, the number of SBM per week, reported for alvimopan, naloxegol and naldemedine, has not been specifically evaluated for methylnaltrexone. For this last drug, there are much data on the rapidity of response to the injection [44]. Further, there are no head-to-head studies, so direct comparisons are not possible. Also, we just examined the data on "efficacy" and "safety." Other aspects would have been interesting as well, e.g., the survival of patients affected by OIC treated or not-treated with PAMORAs like it has been reported for methylnaltrexone in advanced cancer patients [78]. Moreover, between the adverse events, we did not study the abdominal pain evoked by PAMORAs and its relationship with laxation, which has resulted very frequently in some groups of patients $[79,80]$.

\section{Conclusions}

OIC is an important side effect of acute and chronic opioid usage. PAMORAs seem to be effective and relatively safe. Higher doses seem to have more sides effects and also are not always connected with better outcomes. Also, there are specific indications, such as that for alvimopan in postoperative ileus. The different formulations available provide a large armamentarium to the clinicians. For example, palliative care patients and patients with advanced disease could benefit from subcutaneous administration, possibly with methylnaltrexone. While non-cancer patients chronically treated with opioids would be better treated with oral drugs, like naldemedine.

\section{Appendices}

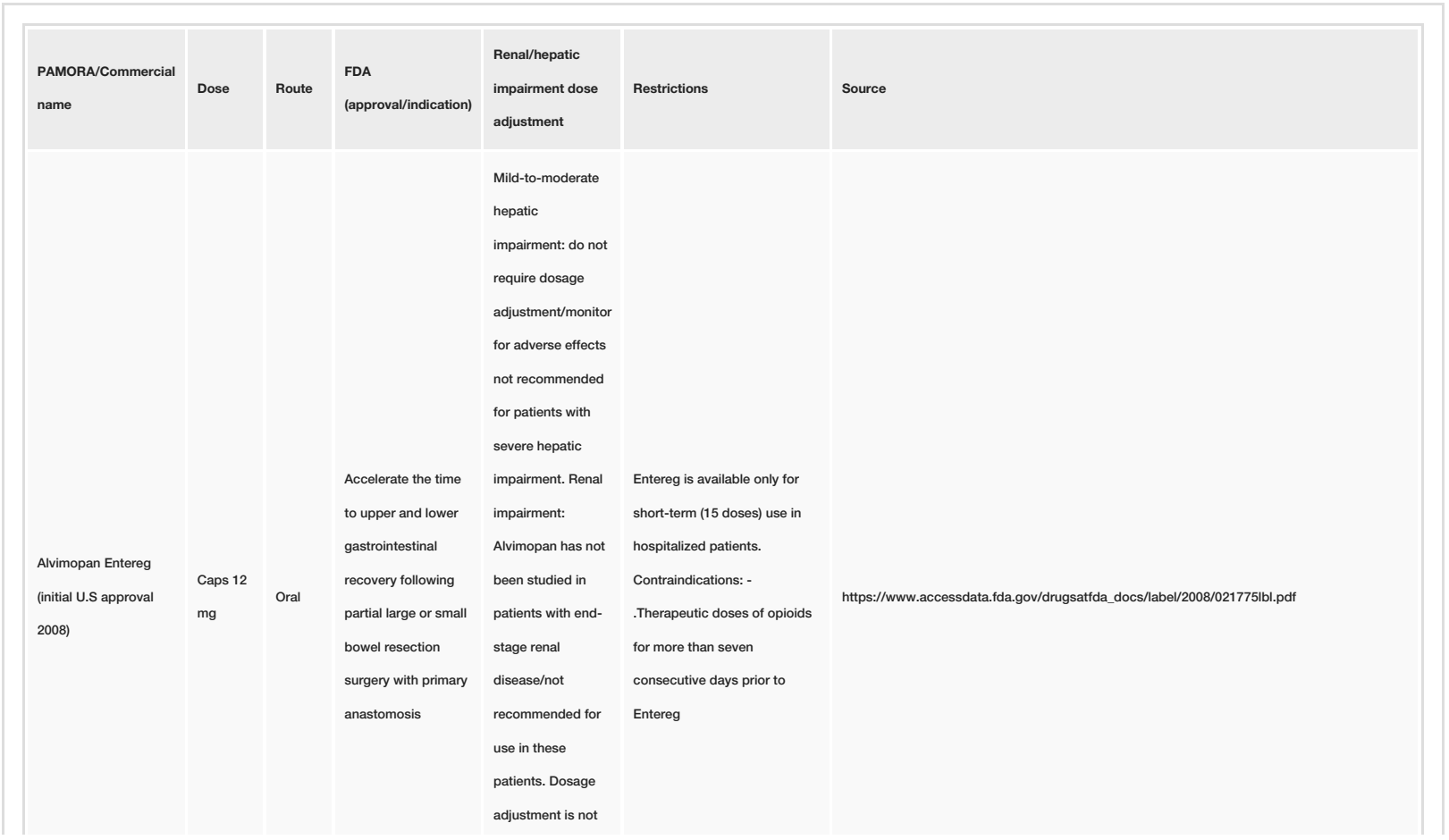




\section{Cureus}

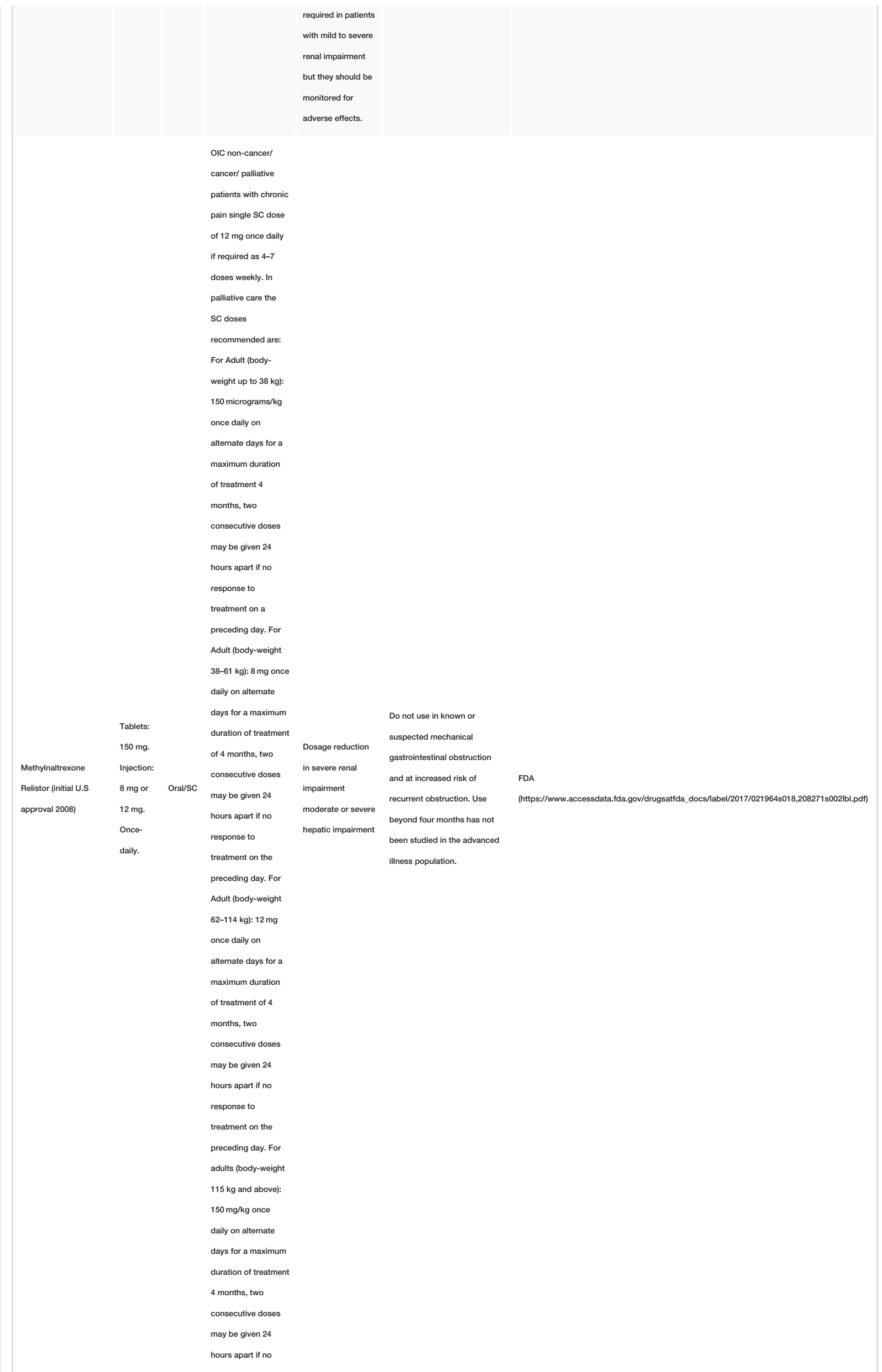




\section{Cureus}

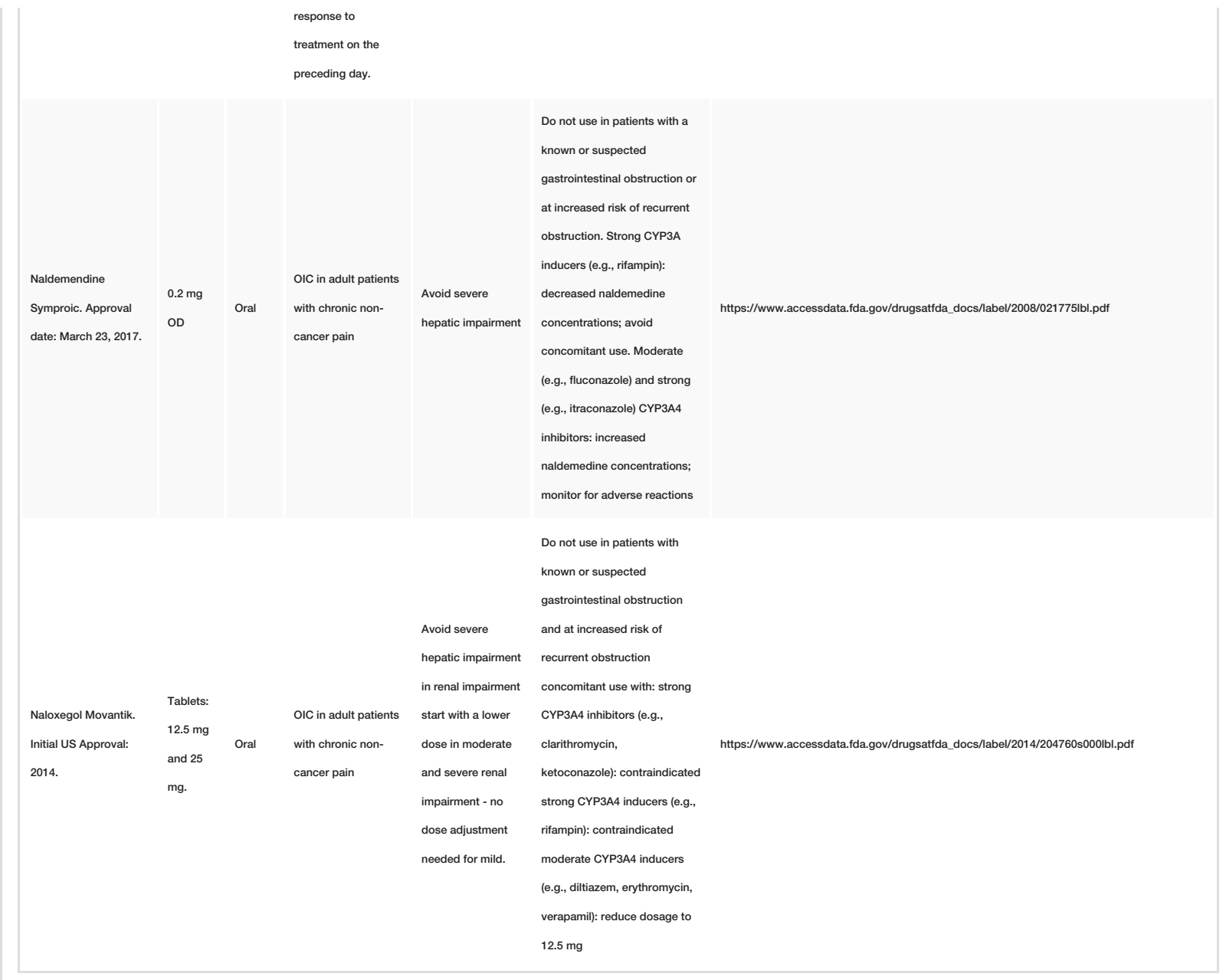

\section{TABLE 8: Supplemental material}

These are the indications of the Food and Drugs Administration (FDA) of the USA for the four PAMORAs [59].

\section{Additional Information}

\section{Disclosures}

Conflicts of interest: In compliance with the ICMJE uniform disclosure form, all authors declare the following: Payment/services info: All authors have declared that no financial support was received from any organization for the submitted work. Financial relationships: All authors have declared that they have no financial relationships at present or within the previous three years with any organizations that might have an interest in the submitted work. Other relationships: All authors have declared that there are no other relationships or activities that could appear to have influenced the submitted work.

\section{Acknowledgements}

This study was fully supported by a grant of the Paolo Procacci Foundation. Open Access Publication was kindly supported by a donation of the Shionogi Italia.

\section{References}

1. Farmer AD, Holt CB, Downes TJ, Ruggeri E, Del Vecchio S, De Giorgio R: Pathophysiology, diagnosis, and management of opioid-induced constipation. Lancet Gastroenterol Hepatol. 2018, 3:203-212. 10.1016/S2468-1253(18)30008-6

2. Varrassi G, Banerji V, Gianni W, Marinangeli F, Pinto C: Impact and consequences of opioid-induced constipation: a survey of patients [PREPRINT]. Pain Ther. 2021, 10.1007/s40122-021-00271-y

3. Ketwaroo GA, Cheng V, Lembo A: Opioid-induced bowel dysfunction. Curr Gastroenterol Rep. 2013, 15:344. 10.1007/s11894-013-0344-2

4. LoCasale RJ, Datto CJ, Margolis MK, Tack J, Coyne KS: The impact of opioid-induced constipation among chronic pain patients with sufficient laxative use. Int J Clin Pract. 2015, 69:1448-56. 10.1111/ijcp.12718

5. Holzer P: Pharmacology of opioids and their effects on gastrointestinal function. Am J Gastroenterol Suppl. 
2014, 2:9-16. 10.1038/ajgsup.2014.4

6. Sternini C, Patierno S, Selmer IS, Kirchgessner A: The opioid system in the gastrointestinal tract . Neurogastroenterol Motil. 2004, 16 Suppl 2:3-16. 10.1111/j.1743-3150.2004.00553.x

7. Galligan JJ, Akbarali HI: Molecular physiology of enteric opioid receptors. Am J Gastroenterol Suppl. 2014, 2:17-21. 10.1038/ajgsup.2014.5

8. Müller-Lissner S, Bassotti G, Coffin B, et al.: Opioid-induced constipation and bowel dysfunction: a clinical guideline. Pain Med. 2017, 18:1837-63. 10.1093/pm/pnw255

9. Grønlund D, Poulsen JL, Krogh K, et al.: The impact of naloxegol on anal sphincter function - using a human experimental model of opioid-induced bowel dysfunction. Eur J Pharm Sci. 2018, 117:187-92. 10.1016/j.ejps.2018.02.008

10. Poulsen JL, Brock C, Grønlund D, Liao D, Gregersen H, Krogh K, Drewes AM: Prolonged-release oxycodone/naloxone improves anal sphincter relaxation compared to oxycodone plus Macrogol 3350. Dig Dis Sci. 2017, 62:3156-66. 10.1007/s10620-017-4784-7

11. Glare P, Walsh D, Sheehan D: The adverse effects of morphine: a prospective survey of common symptoms during repeated dosing for chronic cancer pain. Am J Hosp Palliat Care. 2006, 23:229-35. $10.1177 / 1049909106289068$

12. Tuteja AK, Biskupiak J, Stoddard GJ, Lipman AG: Opioid-induced bowel disorders and narcotic bowel syndrome in patients with chronic non-cancer pain. Neurogastroenterol Motil. 2010, 22:424-30, e96. 10.1111/j.1365-2982.2009.01458.x

13. Drewes AM, Munkholm P, Simrén M, et al.: Definition, diagnosis and treatment strategies for opioidinduced bowel dysfunction - recommendations of the Nordic Working Group. Scand J Pain. 2016, 11:111-22. 10.1016/j.sjpain.2015.12.005

14. Davies A, Leach C, Butler C, et al.: Opioid-induced constipation in patients with cancer: a "real-world," multicentre, observational study of diagnostic criteria and clinical features. Pain. 2021, 162:309-18. 10.1097/j.pain.0000000000002024

15. Abramowitz L, Béziaud N, Labreze L, et al.: Prevalence and impact of constipation and bowel dysfunction induced by strong opioids: a cross-sectional survey of 520 patients with cancer pain: DYONISOS study. J Med Econ. 2013, 16:1423-33. 10.3111/13696998.2013.851082

16. Devulder J, Richarz U, Nataraja SH: Impact of long-term use of opioids on quality of life in patients with chronic, non-malignant pain. Curr Med Res Opin. 2005, 21:1555-68. 10.1185/030079905X65321

17. Bell T, Annunziata K, Leslie JB: Opioid-induced constipation negatively impacts pain management, productivity, and health-related quality of life: findings from the National Health and Wellness Survey. J Opioid Manag. 2009, 5:137-44. 10.5055/jom.2009.0014

18. Lang-Illievich K, Bornemann-Cimenti H: Opioid-induced constipation: a narrative review of therapeutic options in clinical management. Korean J Pain. 2019, 32:69-78. 10.3344/kjp.2019.32.2.69

19. Corli O, Santucci C, Corsi N, Radrezza S, Galli F, Bosetti C: The burden of opioid adverse events and the influence on cancer patients'. J Pain Symptom Manage. 2019, 57:899-908.e6.

10.1016/i.jpainsymman.2019.02.009

20. Candrilli SD, Davis KL, Iyer S: Impact of constipation on opioid use patterns, health care resource utilization, and costs in cancer patients on opioid therapy. J Pain Palliat Care Pharmacother. 2009, 23:23141. 10.1080/15360280903098440

21. Bell TJ, Panchal SJ, Miaskowski C, Bolge SC, Milanova T, Williamson R: The prevalence, severity, and impact of opioid-induced bowel dysfunction: results of a US and European Patient Survey (PROBE 1). Pain Med. 2009, 10:35-42. 10.1111/j.1526-4637.2008.00495.x

22. Ducrotté $\mathrm{P}$, Caussé C: The Bowel Function Index: a new validated scale for assessing opioid-induced constipation. Curr Med Res Opin. 2012, 28:457-66. 10.1185/03007995.2012.657301

23. Aziz I, Whitehead WE, Palsson OS, Törnblom H, Simrén M: An approach to the diagnosis and management of Rome IV functional disorders of chronic constipation. Expert Rev Gastroenterol Hepatol. 2020, 14:39-46. 10.1080/17474124.2020.1708718

24. Mearin F, Lacy BE, Chang L, Chey WD, Lembo AJ, Simren M, Spiller R: Bowel Disorders. Gastroenterology. 2016, 150:1393-407. 10.1053/i.gastro.2016.02.031

25. Liu M, Wittbrodt E: Low-dose oral naloxone reverses opioid-induced constipation and analgesia . J Pain Symptom Manage. 2002, 23:48-53. 10.1016/s0885-3924(01)00369-4

26. Farmer AD, Drewes AM, Chiarioni G, De Giorgio R, O'Brien T, Morlion B, Tack J: Pathophysiology and management of opioid-induced constipation: European expert consensus statement. United European Gastroenterol J. 2019, 7:7-20. 10.1177/2050640618818305

27. Nee J, Zakari M, Sugarman MA, et al.: Efficacy of treatments for opioid-induced constipation: systematic review and meta-analysis. Clin Gastroenterol Hepatol. 2018, 16:1569-1584.e2. 10.1016/i.coh.2018.01.021

28. Ouzzani M, Hammady H, Fedorowicz Z, Elmagarmid A: Rayyan-a web and mobile app for systematic reviews. Syst Rev. 2016, 5:210. 10.1186/s13643-016-0384-4

29. Wells G, Shea B, O'Connell D, et al.: The Newcastle-Ottawa Scale (NOS) for assessing the quality of nonrandomised studies in meta-analyses. 2016.

30. Sterne JAC, Savović J, Page MJ, et al.: RoB 2: a revised tool for assessing risk of bias in randomised trials . BMJ. 2019, 366:14898. 10.1136/bmj.14898

31. Webster L, Chey WD, Tack J, Lappalainen J, Diva U, Sostek M: Randomised clinical trial: the long-term safety and tolerability of naloxegol in patients with pain and opioid-induced constipation. Aliment Pharmacol Ther. 2014, 40:771-9. 10.1111/apt.12899

32. Tack J, Lappalainen J, Diva U, Tummala R, Sostek M: Efficacy and safety of naloxegol in patients with opioid-induced constipation and laxative-inadequate response. United European Gastroenterol J. 2015, 3:471-80. 10.1177/2050640615604543

33. Webster L, Dhar S, Eldon M, Masuoka L, Lappalainen J, Sostek M: A phase 2, double-blind, randomized, placebo-controlled, dose-escalation study to evaluate the efficacy, safety, and tolerability of naloxegol in patients with opioid-induced constipation. Pain. 2013, 154:1542-50. 10.1016/j.pain.2013.04.024

34. Coyne KS, Poon JL, Thompson C, Hu Y, Datto CJ, Sostek M: Translating clinical findings into the patient's 
perspective: post-hoc pooled analysis of bowel movement changes as a predictor of improvement in patients' opioid-induced constipation symptoms and outcomes. Clin Ther. 2017, 39:75-88.

10.1016/j.clinthera.2016.11.012

35. Jansen JP, Lorch D, Langan J, et al.: A randomized, placebo-controlled phase 3 trial (Study SB-767905/012) of alvimopan for opioid-induced bowel dysfunction in patients with non-cancer pain. J Pain. 2011, 12:18593. 10.1016/j.jpain.2010.06.012

36. Webster LR, Israel RJ: Oral methylnaltrexone is efficacious and well tolerated for the treatment of opioidinduced constipation in patients with chronic noncancer pain receiving concomitant methadone. J Pain Res. 2018, 11:2509-16. 10.2147/JPR.S160625

37. Portenoy RK, Thomas J, Moehl Boatwright ML, et al.: Subcutaneous methylnaltrexone for the treatment of opioid-induced constipation in patients with advanced illness: a double-blind, randomized, parallel group, dose-ranging study. J Pain Symptom Manage. 2008, 35:458-68. 10.1016/j.jpainsymman.2007.12.005

38. Thomas J, Karver S, Cooney GA, et al.: Methylnaltrexone for opioid-induced constipation in advanced illness. N Engl J Med. 2008, 358:2332-43. 10.1056/NEJMoa0707377

39. Bull J, Wellman CV, Israel RJ, Barrett AC, Paterson C, Forbes WP: Fixed-dose subcutaneous methylnaltrexone in patients with advanced illness and opioid-induced constipation: results of a randomized, placebo-controlled study and open-label extension. J Palliat Med. 2015, 18:593-600. 10.1089/jpm.2014.0362

40. Iyer SS, Randazzo BP, Tzanis EL, Schulman SL, Zhang H, Wang W, Manley AL: Effect of subcutaneous methylnaltrexone on patient-reported constipation symptoms. Value Health. 2011, 14:177-83. 10.1016/j.jval.2010.11.003

41. Michna E, Blonsky ER, Schulman S, et al.: Subcutaneous methylnaltrexone for treatment of opioid-induced constipation in patients with chronic, nonmalignant pain: a randomized controlled study. J Pain. 2011, 12:554-62. 10.1016/j.jpain.2010.11.008

42. Rauck R, Slatkin NE, Stambler N, Harper JR, Israel RJ：Randomized, double-blind trial of oral methylnaltrexone for the treatment of opioid-induced constipation in patients with chronic noncancer pain. Pain Pract. 2017, 17:820-8. 10.1111/papr.12535

43. Webster LR, Michna E, Khan A, Israel RJ, Harper JR: Long-term safety and efficacy of subcutaneous methylnaltrexone in patients with opioid-induced constipation and chronic noncancer pain: a phase 3, open-label trial. Pain Med. 2017, 18:1496-504. 10.1093/pm/pnx148

44. Rauck RL, Slatkin NE, Stambler N, Israel RJ: Safety of oral methylnaltrexone for opioid-induced constipation in patients with chronic noncancer pain. J Pain Res. 2019, 12:139-50. 10.2147/JPR.S170086

45. Yuan CS, Foss JF, O'Connor M, Osinski J, Karrison T, Moss J, Roizen MF: Methylnaltrexone for reversal of constipation due to chronic methadone use: a randomized controlled trial. JAMA. 2000, 283:367-72. 10.1001/jama.283.3.367

46. Chamberlain BH, Cross K, Winston JL, Thomas J, Wang W, Su C, Israel RJ: Methylnaltrexone treatment of opioid-induced constipation in patients with advanced illness. J Pain Symptom Manage. 2009, 38:683-90. 10.1016/j.jpainsymman.2009.02.234

47. Lipman AG, Karver S, Cooney GA, Stambler N, Israel RJ: Methylnaltrexone for opioid-induced constipation in patients with advanced illness: a 3-month open-label treatment extension study. J Pain Palliat Care Pharmacother. 2011, 25:136-45. 10.3109/15360288.2011.573531

48. Nalamachu SR, Pergolizzi J, Taylor R Jr, et al.: Efficacy and tolerability of subcutaneous methylnaltrexone in patients with advanced illness and opioid-induced constipation: a responder analysis of 2 randomized, placebo-controlled trials. Pain Pract. 2015, 15:564-71. 10.1111/papr.12218

49. Yuan CS, Wei G, Foss JF, O'Connor M, Karrison T, Osinski J: Effects of subcutaneous methylnaltrexone on morphine-induced peripherally mediated side effects: a double-blind randomized placebo-controlled trial. J Pharmacol Exp Ther. 2002, 300:118-23. 10.1124/jpet.300.1.118

50. Wild J, Webster L, Yamada T, Hale M: Safety and efficacy of naldemedine for the treatment of opioidinduced constipation in patients with chronic non-cancer pain receiving opioid therapy: a subgroup analysis of patients $\geqslant 65$ years of age. Drugs Aging. 2020, 37:271-9. 10.1007/s40266-020-00753-2

51. Katakami N, Oda K, Tauchi K, et al.: Phase IIB, randomized, double-blind, placebo-controlled study of naldemedine for the treatment of opioid-induced constipation in patients with cancer. J Clin Oncol. 2017, 35:1921-8. 10.1200/JCO.2016.70.8453

52. Katakami N, Harada T, Murata T, et al.: Randomized phase III and extension studies of naldemedine in patients with opioid-induced constipation and cancer. J Clin Oncol. 2017, 35:3859-66. 10.1200/JCO.2017.73.0853

53. Hale M, Wild J, Reddy J, et al.: Naldemedine versus placebo for opioid-induced constipation (COMPOSE-1 and COMPOSE- 2): two multicentre, phase 3, double-blind, randomised, parallel-group trials. Lancet Gastroenterol Hepatol. 2017, 2:555-64. 10.1016/S2468-1253(17)30105-X

54. Webster LR, Yamada T, Arjona Ferreira JC: A phase 2b, randomized, double-blind placebo-controlled study to evaluate the efficacy and safety of naldemedine for the treatment of opioid-induced constipation in patients with chronic noncancer pain. Pain Med. 2017, 18:2350-60. 10.1093/pm/pnw325

55. Webster LR, Nalamachu S, Morlion B, Reddy J, Baba Y, Yamada T, Arjona Ferreira JC: Long-term use of naldemedine in the treatment of opioid-induced constipation in patients with chronic noncancer pain: a randomized, double-blind, placebo-controlled phase 3 study. Pain. 2018, 159:987-94. 10.1097/j.pain.0000000000001174

56. Saito Y, Yokota T, Arai M, Tada Y, Sumitani M: Naldemedine in Japanese patients with opioid-induced constipation and chronic noncancer pain: open-label Phase III studies. J Pain Res. 2019, 12:127-38. 10.2147/JPR.S175900

57. Tompkins DA, Bigelow GE, Harrison JA, Johnson RE, Fudala PJ, Strain EC: Concurrent validation of the Clinical Opiate Withdrawal Scale (COWS) and single-item indices against the Clinical Institute Narcotic Assessment (CINA) opioid withdrawal instrument. Drug Alcohol Depend. 2009, 105:154-9. 10.1016/j.drugalcdep.2009.07.001

58. 2019 first generic drug approvals. (2019). Accessed: May 28, 2021: https://www.fda.gov/drugs/first-generic- 
drug-approvals/2019-first-generic-drug-approvals.

59. FDA indications for the use of PAMORAs . (2017). Accessed: July 4, 2021:

https://www.accessdata.fda.gov/drugsatfda_docs/label/2008/021775lbl.pdf.

60. Tan EK, Cornish J, Darzi AW, Tekkis PP: Meta-analysis: alvimopan vs. placebo in the treatment of postoperative ileus. Aliment Pharmacol Ther. 2007, 25:47-57. 10.1111/j.1365-2036.2006.03150.x

61. Vaughan-Shaw PG, Fecher IC, Harris S, Knight JS: A meta-analysis of the effectiveness of the opioid receptor antagonist alvimopan in reducing hospital length of stay and time to GI recovery in patients enrolled in a standardized accelerated recovery program after abdominal surgery. Dis Colon Rectum. 2012, 55:611-20. 10.1097/DCR.0b013e318249fc78

62. Hanna P, Regmi S, Kalapara A, et al.: Alvimopan as part of the Enhanced Recovery After Surgery protocol following radical cystectomy is associated with decreased hospital stay. Int J Urol. 2021, 28:696-701. 10.1111/iju.14546

63. Dunn LK, Thiele RH, Lin MC, et al.: The impact of alvimopan on return of bowel function after major spine surgery - a prospective, randomized, double-blind study. Neurosurgery. 2019, 85:E233-9. 10.1093/neuros/nyz005

64. Hensley P, Higgins M, Rasper A, et al.: Efficacy and safety of alvimopan use in benign urinary tract reconstruction. Int Urol Nephrol. 2021, 53:77-82. 10.1007/s11255-020-02621-9

65. Mehta N, O'Connell K, Giambrone GP, Baqai A, Diwan S: Efficacy of methylnaltrexone for the treatment of opiod-induced constipation: a meta-analysis and systematic review. Postgrad Med. 2016, 128:282-9. 10.1080/00325481.2016.1149017

66. Lin AJ, Costandi AJ, Kim E, et al.: Improved bowel function with oral methylnaltrexone following posterior spinal fusion for adolescent idiopathic scoliosis. J Pediatr Orthop. 2021, 10.1097/BPO.0000000000001854

67. Blackney KA, Kamdar NV, Liu CA, Edwards DA: Methylnaltrexone-associated bowel perforation in postoperative opioid-induced constipation and Ogilvie syndrome. A A Pract. 2019, 12:44-6. 10.1213/XAA.0000000000000840

68. Mackey AC, Green L, Greene P, Avigan M: Methylnaltrexone and gastrointestinal perforation. J Pain Symptom Manage. 2010, 40:e1-3. 10.1016/j.jpainsymman.2010.01.011

69. Garnock-Jones KP: Naloxegol: a review of its use in patients with opioid-induced constipation . Drugs. 2015, 75:419-25. 10.1007/s40265-015-0357-2

70. Moventig. (2014). Accessed: May 28, 2021: https://www.ema.europa.eu/en/medicines/human/EPAR/moventig.

71. Esmadi M, Ahmad D, Hewlett A: Efficacy of naldemedine for the treatment of opioid-induced constipation: a meta-analysis. J Gastrointestin Liver Dis. 2019, 28:41-6. 10.15403/igld.2014.1121.281.any

72. Song X, Wang D, Qu X, Dong N, Teng S: A meta-analysis of naldemedine for the treatment of opioidinduced constipation. Expert Rev Clin Pharmacol. 2019, 12:121-8. 10.1080/17512433.2019.1570845

73. Osaka I, Ishiki H, Yokota T, Tada Y, Sato H, Okamoto M, Satomi E: Safety and efficacy of naldemedine in cancer patients with opioid-induced constipation: a pooled, subgroup analysis of two randomised controlled studies. ESMO Open. 2019, 4:e000527. 10.1136/esmoopen-2019-000527

74. Fukumura K, Yamada T, Yokota T, Kawasaki A: The influence of renal or hepatic impairment on the pharmacokinetics, safety, and tolerability of naldemedine. Clin Pharmacol Drug Dev. 2020, 9:162-74. 10.1002/cpdd.690

75. Webster LR, Hale ME, Yamada T, Wild JE: A renal impairment subgroup analysis of the safety and efficacy of naldemedine for the treatment of opioid-induced constipation in patients with chronic non-cancer pain receiving opioid therapy. J Pain Res. 2020, 13:605-12. 10.2147/JPR.S237833

76. Drug trials snapshots: SYMPROIC. (2017). Accessed: May 28, 2021: https://www.fda.gov/drugs/drugapprovals-and-databases/drug-trials-snapshots-symproic..

77. Alvaro D, Caraceni AT, Coluzzi F, et al.: What to do and what not to do in the management of opioidinduced constipation: a choosing wisely report. Pain Ther. 2020, 9:657-67. 10.1007/s40122-020-00195-Z

78. Janku F, Johnson LK, Karp DD, Atkins JT, Singleton PA, Moss J: Treatment with methylnaltrexone is associated with increased survival in patients with advanced cancer. Ann Oncol. 2016, 27:2032-8. 10.1093/annonc/mdw317

79. Slatkin NE, Lynn R, Su C, Wang W, Israel RJ: Characterization of abdominal pain during methylnaltrexone treatment of opioid-induced constipation in advanced illness: a post hoc analysis of two clinical trials. J Pain Symptom Manage. 2011, 42:754-60. 10.1016/j.jpainsymman.2011.02.015

80. Zhang YY, Zhou R, Gu WJ: Efficacy and safety of methylnaltrexone for the treatment of opioid-induced constipation: a meta-analysis of randomized controlled trials. Pain Ther. 2021, 10:165-79. 10.1007/s40122021-00237-0 